Review Article

\title{
Current Developments in Pt(IV) Prodrugs Conjugated with Bioactive Ligands
}

\author{
Xuejiao Li, ${ }^{1}$ Yahong Liu $(\mathbb{D})^{2}$ and Hongqi Tian ${ }^{1}{ }^{1}$ \\ ${ }^{1}$ Tianjin Key Laboratory of Radiation Medicine and Molecular Nuclear Medicine, Institute of Radiation Medicine, \\ Chinese Academy of Medical Sciences and Peking Union Medical College, Tianjin 300192, China \\ ${ }^{2}$ Tianjin Binjiang Pharma, Inc., Tianjin 300192, China
}

Correspondence should be addressed to Hongqi Tian; tianhongqi@irm-cams.ac.cn

Received 24 May 2018; Revised 19 August 2018; Accepted 6 September 2018; Published 1 October 2018

Academic Editor: Imre Sovago

Copyright (C) 2018 Xuejiao Li et al. This is an open access article distributed under the Creative Commons Attribution License, which permits unrestricted use, distribution, and reproduction in any medium, provided the original work is properly cited.

To overcome the side effects of and resistance to cisplatin, a variety of $\mathrm{Pt}(\mathrm{IV})$ prodrugs were designed and synthesized via different modifications including combination with lipid chains to increase hydrophobicity, conjugation with short peptide chains or nanoparticles to improve drug delivery, or addition of bioactive ligands to the axial positions of Pt(IV) complexes to exert dualfunction effects. This review summarizes the recent progress in the development of Pt(IV) prodrugs conjugated with bioactivetargeting ligands, including histone deacetylase inhibitors, p53 agonists, alkylating agents, and nonsteroidal anti-inflammatory agents. Although $\mathrm{Pt}(\mathrm{IV})$ complexes that conjugated with bioactive ligands show satisfactory anticancer effects, none has been approved for clinical use. Therefore, we hope that this review will contribute to further study and development of Pt(IV) complexes conjugated with bioactive and other ligands.

\section{Introduction}

Since the antitumor activity of cisplatin was serendipitously discovered by Rosenberg et al. in 1965 [1, 2], development of platinum anticancer agents has attracted the attention of numerous investigators. Although relatively few agents have been used as drugs clinically, the clinical value created is immeasurable. Currently, three platinum-based anticancer drugs, cisplatin, carboplatin, and oxaliplatin, have been approved by the U.S. Food and Drug Administration (FDA) and are used worldwide [3-5]. In addition, nedaplatin, heptaplatin, and lobaplatin have been approved for use in Japan, China, and South Korea, respectively [6]. The structures of these platinum drugs are shown in Figure 1.

According to statistics, platinum-based anticancer agents are clinically used to treat $50 \%$ of malignant cancers including testicular, ovarian, cervical, breast, and bladder cancers, as well as cancers of the head and neck, esophageal and lung cancers, mesothelioma, brain tumors, and neuroblastoma [6,7]. When platinum-based drugs enter cells by passive or facilitated diffusion or active transport and are activated by aquation, their antineoplastic effects are linked to multiple mechanisms such as oxidative stress and mitochondrial DNA damage $[8,9]$. However, their primary mechanism is attacking genomic DNA by covalently binding to the N7 position of guanine and adenine to form nuclear DNA adducts. This process inhibits transcription and replication, resulting in cell apoptosis.

Unfortunately, Pt(II)-based complexes, with their original structure-activity relationship summarized by Cleare and Hoeschele in 1973 [10], have numerous drawbacks including low bioavailability, severe side effects, poor stability, and inherent or acquired resistance [11]. Although multiple nonclassical Pt(II)-based complexes were designed and explored to overcome the shortcomings, such as transplatinum, monofunctional, or polynuclear platinum complexes, no great success has been achieved yet.

To overcome the drawbacks of Pt(II)-based complexes, $\mathrm{Pt}(\mathrm{IV})$ complexes have been designed and synthesized as prodrugs. Pt(IV) complexes exhibit kinetic inertness and a low-spin $d^{6}$ octahedral geometry, rendering them more stable for oral administration. Furthermore, modification of axial ligands can enhance pharmacological properties and reduce side effects and drug resistance [12]. In cells, Pt(IV) 


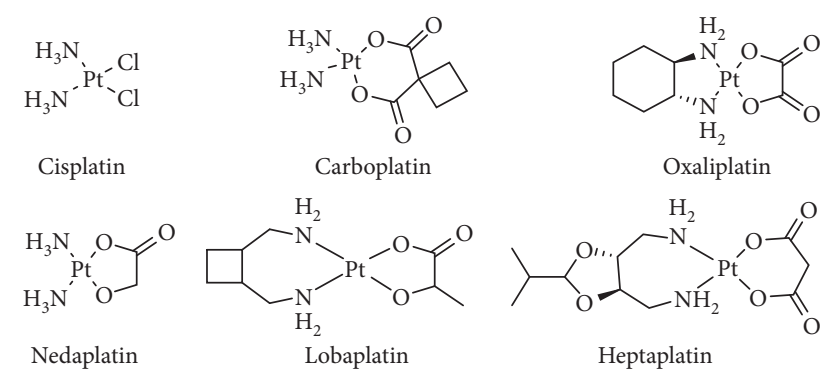

FIgURE 1: Pt(II) anticancer drugs approved for treatment.

complexes are activated by reductive elimination to release active products; namely, Pt(II) drugs, which exert antitumor activity but in contrast to cisplatin, are not hydrolyzed or ligand-substituted [13]. Satraplatin represents the most successful $\mathrm{Pt}(\mathrm{IV})$ prodrug, which progressed to a phase III clinical trial of hormone-refractory prostate cancer (PC); however, the overall survival was not significantly improved. Ormaplatin (tetraplatin), iproplatin, and LA-12 have also progressed to clinical studies [14].

The current strategies for development of $\mathrm{Pt}(\mathrm{IV})$ complexes can be categorized into attachment of $\mathrm{Pt}(\mathrm{IV})$ to nanoparticles to increase bioavailability; synthesis of targeted $\mathrm{Pt}(\mathrm{IV})$ complexes to increase lipophilicity, facilitate cellular accumulation, and reduce side effects; and development of theranostic and photoactivatable prodrugs $[7,15,16]$. In this review, we focus on bifunctional targeting $\mathrm{Pt}(\mathrm{IV})$ prodrugs, paying particular attention to their molecular targets and antitumor effects. Although brief summaries of bifunctional $\mathrm{Pt}(\mathrm{IV})$ prodrugs have been provided in several articles $[7,12,17]$, no review has provided an indepth discussion of design details of targeted molecules and enhancement of their antitumor effects. Therefore, we summarized in detail Pt(IV) drug targeting and improved efficacy over the last 5 years to lay a theoretical foundation for the development of targeted Pt(IV) prodrugs conjugated with bioactive ligands.

\section{Bifunctional Pt(IV) Prodrugs}

The rational design of bifunctional $\mathrm{Pt}(\mathrm{IV})$ prodrugs relies on the reduction reaction of $\mathrm{Pt}(\mathrm{IV})$ to yield the corresponding active $\mathrm{Pt}(\mathrm{II})$ species and a biologically active ligand, improving the accumulation and activity of platinum drugs or helping them overcome drug resistance. Presently, the main $\mathrm{Pt}(\mathrm{IV})$ cores are cisplatin, carboplatin, and oxaliplatin, while bioactive ligands include histone deacetylase (HDAC) inhibitors, cyclooxygenase (COX) inhibitors, p53 inhibitors, and casein kinase 2 (CK2) inhibitors. Here, we summarize the current progress in the development of $\mathrm{Pt}(\mathrm{IV})$ prodrugs with various bioactive ligands.

2.1. Targeting $H D A C$. The nucleosome is composed of four core histones ( $\mathrm{H} 3, \mathrm{H} 4, \mathrm{H} 2 \mathrm{~A}$, and $\mathrm{H} 2 \mathrm{~B})$ wrapped around with 147 base pairs of DNA [18]. It is the fundamental unit of chromatin, which regulates various cell processes such as DNA condensation, transcription, repair, and replication.
Therefore, the status of histones is a key player in DNA transcription [19]. One of the most important histone modifications is acetylation of lysine residues, which is regulated by the equilibrium between two groups of enzymes, histone acetyltransferases (HATs), and HDACs [20]. HATs catalyze acetylation of histone lysine residues and neutralize the positive charge of histone tails, resulting in a more open chromatin state and making it more accessible to the transcriptional apparatus. In contrast, HDACs catalyze the removal of acetyl groups from lysine residues of histone tails, leading to chromatin condensation and transcriptional repression [21]. In the last decades, numerous HDAC inhibitors have shown good anticancer activities via different processes in various cell types and on multiple targets [22-25]. Based on their chemical structures, HDAC inhibitors include short-chain fatty acids, hydroxamic acids, synthetic benzamides, and cyclic peptides, which exhibit various bioactivities and specificities. Interestingly, it has been reported that DNA-damaging agents such as platinum drugs showed improved therapeutic profiles in combination with HDAC inhibitors since the latter could expose nuclear DNA to cytotoxic DNA-damaging agents, enhancing the efficacy of platinum drugs [26-28].

\subsubsection{Pt(IV) Conjugated with Valproic Acid (VPA).} Based on the above data, Yang et al. [29] have designed and synthesized a bifunctional $\mathrm{Pt}(\mathrm{IV})$ prodrug, VAAP (Figure 2(1)), based on oxidized cisplatin (diaminedichlorodihydroxyplatinum and ACHP) and an HDAC inhibitor, valproic acid (VPA), for cancer chemotherapy. The cytotoxicity of VAAP against A549, BCap-37, SKOV3 , and HepG2 cells was significantly higher than that of ACHP by 90-, 51-, 33-, and 73-fold, respectively. Furthermore, the cytotoxicity of VAAP was higher than that of cisplatin; thus, the half-maximal (50\%) inhibitory concentration $\left(\mathrm{IC}_{50}\right)$ value of VAAP was 12 times lower than that of cisplatin for the A549 cell line, while that of VPA was in the millimolar range, i.e., the same as reported in the literature $[26,30]$. In addition, researchers have found that VAAP markedly induced cell death through apoptosis and cell-cycle arrest in the S phase. A mechanistic study has shown that although VPA facilitated the rapid entry of ACHP into cells, the cytosolic ACHP was rapidly removed. However, VAAP not only efficiently attached to the cell membrane but also improved the cytosolic platinum concentration, resulting in enhanced cytotoxicity. Remarkably, in comparison to the 50-100-fold improvement of the $\mathrm{IC}_{50}$ value, the cytosolic platinum concentration was only approximately twice that of ACHP after cells were treated with VAAP for $24 \mathrm{~h}$. Studies have suggested that the high cytotoxicity of VAAP resulted from the combination of high cytosolic platinum concentration and synergy between the resulting $\mathrm{Pt}(\mathrm{II})$ and VPA. Unfortunately, the activity of HDAC was not tested in cells or a A549 tumor xenograft mouse model, although VAAP was confirmed to inhibit HDAC in the presence of ascorbic acid in a cell-free system. It is encouraging that VAAP significantly 


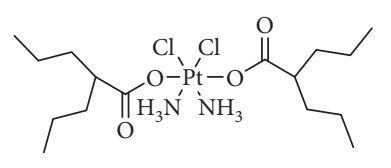

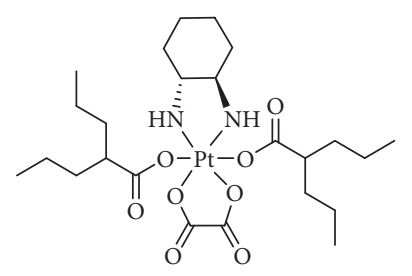

2
Figure 2: Structure of $\mathrm{Pt}(\mathrm{IV})$ prodrugs based on valproic acid (VPA).

increased the antitumor activity, prolonged the blood circulation times, and decreased the nephrotoxicity in vivo compared with the effects of ACHP.

Alessio et al. [31] have synthesized VAAP again for the treatment of malignant pleural mesothelioma (MPM). Currently, the combination of cisplatin with the antifolate agent pemetrexed is considered a gold-standard frontline chemotherapy for MPM [32], while VAAP as a single drug displayed remarkable activity against a panel of cancer cells, especially MPM-derived cells in the study by Yang et al. [29]. The results of Alessio et al. [31] also indicated that the high lipophilicity of VAAP facilitated its passive diffusion, resulting in increased accumulation of platinum in the cells. Moreover, medium-chain fatty acid transport or caveolaemediated endocytosis did not seem to be involved in this process. Interestingly, the authors demonstrated that there was no synergism, and the higher cytotoxicity of the Pt(IV) prodrug was solely due to the higher accumulation of $\mathrm{Pt}(\mathrm{II})$. The released intracellular VPA exhibited no specific effects on cellular biochemical processes since the concentration of VPA released by reduction was too low to exert any HDAC inhibitory activity, which contradicted the conclusions of Yang et al. [29]. In addition, Alessio and coworkers studied the biochemical behavior of Pt-VPA entrapped in liposomes and demonstrated much higher cellular accumulation of lipoPt-VPA; however, the antiproliferative effect increased only twofold, and thus, further studies of specific mechanisms are needed.

Because of the inconclusive reports on the role of HDAC inhibition in the mechanism of the toxicity of VAAP against tumor cells, Novohradsky et al. [33] reevaluated the mechanism of cytotoxicity of $\mathrm{Pt}(\mathrm{IV})$-VPA derivatives, focusing on the previously published contradictory conclusions. These authors confirmed that the $\mathrm{Pt}(\mathrm{IV})$ derivatives of cisplatin conjugated with VPA accumulated in and killed cancer cells with a greater efficacy than that of cisplatin owing to the considerably higher binding of VPAcontaining platinum to DNA. This superior effect was mainly attributed to increased hydrophobicity. Most importantly, cellularly, the $\mathrm{Pt}(\mathrm{IV})$ complexes remarkably inhibited HDAC activity, reduced the expression of HDAC enzymes, and induced distinct rates of histone $\mathrm{H} 3$ hyperacetylation in cisplatin-sensitive (A2780) and cisplatinresistant (A2780cisR) ovarian cancer cells, resulting in chromatin decondensation. Moreover, the $\mathrm{Pt}(\mathrm{IV}) \mathrm{de}-$ rivatives of cisplatin conjugated with VPA reduced the level of glutathione (GSH) in tumor cells with more pronounced in A2780cisR than in A2780 cells. In summary, the results indicated that the enhanced antitumor effect resulted from both improved cellular accumulation of platinum and VPA, released by intracellular reduction of $\mathrm{Pt}(\mathrm{IV})$ prodrugs, and multiple bioactivities of VPA.

In addition, Novohradsky's team synthesized a new bifunctional $\mathrm{Pt}(\mathrm{IV})$ complex (Figure 2(2)) based on oxaliplatin [34] to overcome the limitation of the clinical use of cisplatin. Although the cytotoxicity of the Pt(IV) complex was lower than that of oxaliplatin, the results showed that free VPA released from the Pt(IV) complex reduced the activity of HDACs and upregulated the expression of the histone $\mathrm{H} 3$ protein complexed with DNA, leading to an enhanced cytotoxicity to tumor cells, which was attributed to the synergism between $\mathrm{Pt}(\mathrm{II})$ and $\mathrm{VAP}$, released by reduction of the complex in tumor cells.

\subsubsection{Pt(IV) Complexes Conjugated with 4-Phenylbutyric} Acid $(\mathrm{PhB})$. Using another HDAC inhibitor, 4-phenylbutyric acid (PhB), Raveendran et al. [35] synthesized a new class of $\mathrm{Pt}(\mathrm{IV})$ derivatives based on the cores of cisplatin and oxaliplatin (Figure 3(3 and 4)) and compared their bioactivities to those of $\mathrm{Pt}(\mathrm{IV})$ derivatives conjugated with VPA. The researchers found that the Pt(IV) derivatives of cisplatin were more potent than those of oxaliplatin, which was consistent with the data of previous reports. $\mathrm{Pt}(\mathrm{IV})$ derivatives of cisplatin with a bis- $\mathrm{PhB}$ derivative (VI) were approximately 5and 100-fold more potent than a bis-VPA analog and cisplatin, respectively, suggesting that $\mathrm{PhB}$ was more effective than VPA in promoting cytotoxicity. Furthermore, the HDAC inhibitory activity of the bis- $\mathrm{PhB}$ analog in cancer cells was $60-70 \%$ at concentrations lower than the $\mathrm{IC}_{50}$ of $\mathrm{PhB}$, indicating a synergism between platinum and $\mathrm{PhB}$. The enhanced effect was associated with the rates of cellular accumulation and Pt-DNA binding, not with the hydrophobicity, as concluded based on $\log \mathrm{P}$ values.

Further mechanistic studies have revealed that $\mathrm{Pt}(\mathrm{IV})$ derivatives conjugated with $\mathrm{PhB}$ induced tumor cell apoptosis through the mitochondrial pathway. This was associated with the activation of caspase-3, -9 , and -7 (involved in the intrinsic apoptosis pathway) and the reduction of the mitochondrial membrane potential, which was p53independent, unlike the mechanism of action of cisplatin. Therefore, the "dual-action" complexes are, in fact, "multiaction" complexes triggering several different pathways, which exert antitumor effects together. Recently, Almotairy et al. [36] prepared Pt(IV) complexes with PBA based on the carboplatin scaffold (Figure 3(5)); however, the increase in antitumor activity was lower than that induced by cisplatin analogs. In addition, Harper et al. [37] designed $\mathrm{Pt}(\mathrm{IV})$ derivatives of $[\mathrm{Pt}(1 S, 2 S$-diaminocyclohexane) (5,6-dimethyl-1,10-phenanthroline)] (Pt56MeSS, Figure 3(6)), with two PhBs, which displayed a relatively minor association between the axial ligands and the potency of the compounds, while the average $\mathrm{IC}_{50}$ values were better than that of cisplatin.

2.1.3. Pt(IV) Complex Conjugated with Suberoyl-bisHydroxamic Acid (SubH). Suberoyl-bis-hydroxamic acid 


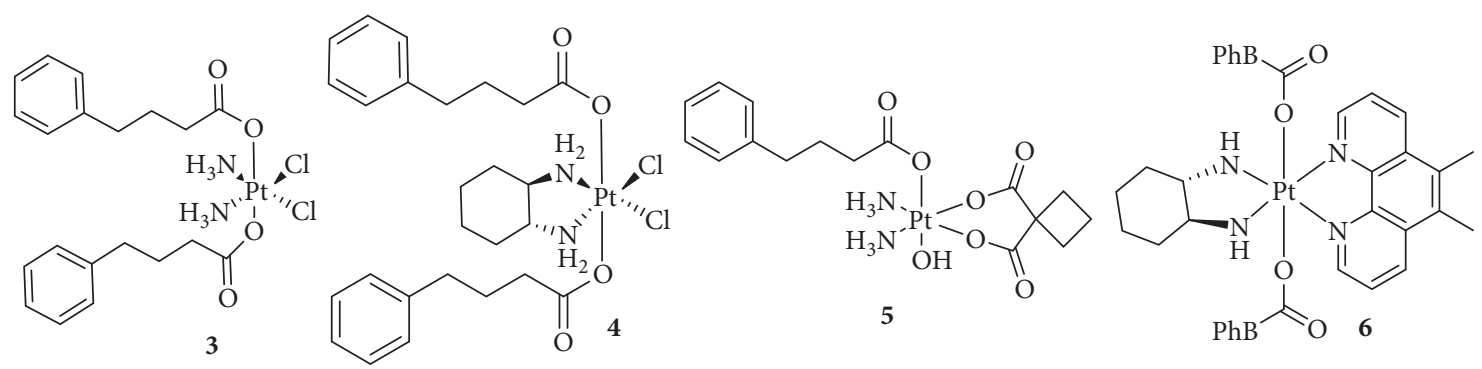

Figure 3: Structure of $\mathrm{Pt}(\mathrm{IV})$ prodrugs based on 4-phenylbutyric acid (PhB).

(SubH) shows HDAC inhibitory activity at submicromolar concentrations and antitumor effects at micromolar concentrations. Furthermore, following its conjugation with $\mathrm{Pt}$ (II) complexes, SubH displayed potent synergistic interactions [38-40]. Interestingly, Kasparkova et al. [41] added two SubHs to a nontoxic Pt(IV)-azido complex to form a photoactivatable $\mathrm{Pt}(\mathrm{IV})$ complex (Figure 4(7)), which exhibited a higher efficacy in photodynamic anticancer chemotherapy. Following irradiation with ultraviolet A (UVA), the cytotoxicity of $\mathrm{Pt}(\mathrm{IV})$ significantly increased by $6-11$-fold than that of cisplatin, which was not affected by light.

Under UVA or visible light, the Pt(IV) complex was activated, and the released Pt(II) was bound to DNA, while the released SubH inhibited HDAC activity, leading to improved $\mathrm{H} 3$ acetylation. More importantly, the activated SubH-conjugated Pt(IV) complex inhibited the prolongation of RNA transcription by blocking RNA polymerase II and destroying the global structure of DNA, which was not observed in the dark. This strategy based on the light-induced simultaneous HDAC inhibition and DNA damage by platinum drugs provided a new method for the development of "dual-action" $\mathrm{Pt}(\mathrm{IV})$ prodrugs.

2.2. Targeting p53. In 1989, tumor protein p53 was first reported by Finlay et al. [42] as an inhibitor of oncogenemediated transformation, associated with cell-cycle arrest or apoptotic activities. Many studies have shown that p53regulated cell cycle arrest or apoptosis is important for the inhibition of tumor development, and p53 is involved in multiple cellular processes such as oncogene activation, DNA damage, DNA repair, metabolism, and antioxidant responses [43]. Mutations in p53 contribute to tumor formation or drug resistance. In fact, p53 was named the "guardian angel" of genome integrity [44]. However, the human murine double minute 2 (MDM2) oncoprotein mediates and inhibits p53 function through direct interactions [45]. Therefore, a small molecule inhibitor designed to block the p53-MDM2 interaction might be effective in treating human cancers retaining wild-type p53. Chalcone, a well-known p53-MDM2 inhibitor, binds to the p53 pocket on MDM2 to inhibit the p53-MDM2 interaction at a micromolar range concentration [46]. Ma and colleagues [47] designed a novel, dual-targeting $\mathrm{Pt}(\mathrm{IV})$ anticancer prodrug, chalcoplatin, based on cisplatin and chalcone, which not only formed Pt-DNA adducts but also activated the p53 pathway (Figure 5(8)). The results showed that, compared to cisplatin, chalcoplatin exhibited

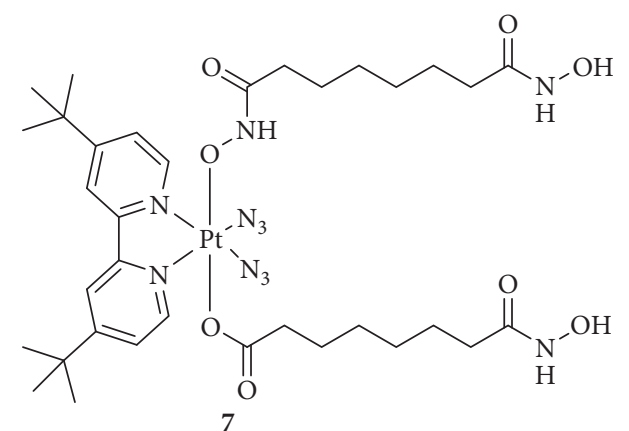

FIgURE 4: Structure of $\mathrm{Pt}(\mathrm{IV})$ prodrugs based on suberoyl-bishydroxamic acid (SubH).<smiles>N[P+](N)(OC(=O)COc1ccc(/C=C/C(=O)c2ccc(Cl)c(Cl)c2)cc1)OC(=O)COc1ccc(/C=C/C(=O)c2ccc(Cl)c(Cl)c2)cc1</smiles>

Figure 5: Structure of Pt(IV) prodrugs based on chalcone.

a markedly higher cytotoxicity (10-fold) for wild-type p53 cells but not for p53 null cells. Although the cellular accumulation increased, the Pt-DNA binding rate was not improved. Moreover, chalcoplatin mainly induced cell cycle arrest in the $\mathrm{S}$ and $\mathrm{G} 2 / \mathrm{M}$ phases, whereas cisplatin and chalcone caused cell cycle arrest in the $\mathrm{S}$ and G2/M phases, respectively. These results indicated that the chalcone moiety in chalcoplatin played a pivotal role in killing cancer cells, possibly by activating $\mathrm{p} 53$. In fact, chalcoplatin more effectively promoted the expression of p53 than cisplatin. Unfortunately, although chalcoplatin showed distinct effects on cisplatin-resistant $\mathrm{A} 549$ cells $\left(\mathrm{IC}_{50}, 50.5\right.$, and $1.6 \mu \mathrm{M}$ for cisplatin and chalcoplatin, respectively), the specific mechanism was not studied.

2.3. Targeting DNA. DNA-damaging agents play a key role in anticancer chemotherapeutics and are widely used clinically [48]. In addition to platinum drugs, DNA-alkylating agents are essential components and include nitrogen mustards that represent the earliest and most widely studied DNA cross-linking agents such as cyclophosphamide, 
chlorambucil (Chl), and melphalan. Chl has been approved by the FDA and is primarily used in the treatment of chronic lymphocytic leukemia and other cancers, including nonHodgkin lymphoma, certain types of trophoblastic neoplasms, and ovarian carcinoma [49-51]. Chl, which possesses an $N, N$-bis (2-chloroethyl)amine functional group, has reactive electrophiles and covalently binds to DNA at the N3 or N7 position of adenine or N7 position of guanine to inhibit DNA replication and transcription [52]. However, serious drug resistance and toxicities hindered its clinical application, similar to $\mathrm{Pt}(\mathrm{II})$ complexes. Based on this, Chen et al. $[53,54]$ synthesized a series of $\mathrm{Pt}(\mathrm{IV})$ derivatives by conjugating a Chl unit with cisplatin, oxaliplatin, and carboplatin analogs (Figure 6(9 and 10)). These Pt(IV) complexes not only exhibited significant antitumor activities but also overcame the drug resistance of cisplatin-resistant cancer cells. One of the most critical factors was that the free Chl released from the $\mathrm{Pt}(\mathrm{IV})$ complexes synergistically increased DNA damage induced by the released $\mathrm{Pt}(\mathrm{II})$ complexes. Moreover, Chl blocked the double-strand break repair by suppressing the double-strand break repair MRE11-RAD50-NBS1 (MRN) protein complex, decreasing CK2 phosphorylation, and reducing the expression of proline-rich acidic protein 1 (PRAP1). These effects increased the phosphorylation of histone H2A histone family, member $\mathrm{X}(\mathrm{H} 2 \mathrm{AX})$, which is closely related to drug resistance in tumor cells. More importantly, some complexes exhibited a longer blood retention time and nearly no toxicities in vivo, suggesting their potential as platinumbased anticancer drug candidates.

The DNA damage response (DDR) network plays a key role in the maintenance of genomic integrity and regulation of the efficacy of anticancer drugs. The DDR network mainly consists of DNA damage recognition and repair pathways, which involve multiple signaling molecules including MRN, ataxia telangiectasia mutated (ATM), ATM and Rad3related protein (ATR), checkpoint kinase 1 (CHK1), $\mathrm{X}$-ray repair cross-complementing protein 1 (XRCC1), mediator of DNA damage checkpoint protein 1 (MDC1), CK2, $\gamma \mathrm{H} 2 \mathrm{AX}$, WEE1 G2 checkpoint kinase, XPA DNA repair protein, excision repair 1 protein (ERCC1), and ERCC1-ERCC4 complex. These molecules are associated with survival and resistance and therefore, are attractive targets for cancer therapy. For example, Chen et al. [55] used the CK2 inhibitor CX-4945 as an axial ligand to design a Pt(IV) prodrug (Figure 7(11)), Cx-platin, which disrupted DDR through the suppression of CK2-phosphorylated MDC1, thereby combining the forkhead-associated domain of aprataxin with DNA double-strand breaks and finally inducing apoptosis in a panel of cancer cells, similar to Chl, in response to DNA damage. Wang et al. [56] also synthesized a Pt(IV) anticancer prodrug targeting nucleotide excision repair (NER) by adding a NER inhibitor, $(E)-2-([\{8 \mathrm{a}, 9 \mathrm{a}$-dihydro- $9 H$-fluoren9-ylidene\}hydrazono]methyl)benzoic acid (Figure 7(12)), to axial positions of oxidized cisplatin to overcome the cisplatin resistance. The NER inhibitor-Pt(IV) complex showed a 22and 3.54-fold higher cytotoxicity against A2780cisR and A549cisR cells, respectively, than against A2780 and A549 cells, by inducing high levels of Pt-GG intrastrand crosslinks. The model of biofunctional Pt(IV) prodrugs inhibiting DDR provides a strategy to conquer the resistance to cisplatin.

2.4. Targeting Hypoxia-Inducible Factor (HIF). Hypoxia plays a critical role in the development of cancer and is caused by an inadequate supply of oxygen (median concentration, 0-4\%) [57]. Hypoxia is a hallmark in many solid tumors. Approximately $70 \%$ of cancer cells respond to hypoxia by increasing the expression of the hypoxiainducible factor (HIF)-1, which can translocate to the nucleus and activate the relative transcription of genes involved in tumorigenesis [58]. Unlike a normoxic microenvironment, the hypoxic tumor microenvironment can weaken the antitumor effects of Pt(II) drugs. Xu et al. [59] developed two novel Pt(IV) anticancer prodrugs, YCC-1 (Figure 8(13)) and YCC-2 (Figure 8(4)), which not only enhanced the platination of DNA but also inhibited the expression of HIF- $1 \alpha$ via release of HIF- $1 \alpha$ inhibitors from YCC-1 and, especially, from YCC-2 under hypoxia but not normoxia, thus significantly enhancing the sensitivity of tumor cells to cisplatin. The unique difference between the structures of YCC1 and YCC-2 was that the axial chloride group of YCC-1 was substituted with a hydroxyl group in YCC-2, suggesting that axial ligands such as a chloride or hydroxyl group also affect the bioactivity of $\mathrm{Pt}(\mathrm{IV})$ complexes. In vivo, YCC-2 effectively inhibited HCT-116 tumor growth, without much toxicity, based on the slight weight change of mice. This study provided a new approach to increase the effect of chemotherapeutic drugs.

2.5. Targeting COX. Chronic inflammation occurs in approximately $20 \%$ of human cancers and plays an important role in tumor growth and metastatic progression [60]. Clinical data have suggested that tumor progression is often accompanied by chronic inflammation related to increased COX expression, including COX-1 and COX-2, which are the crucial enzymes in prostaglandin biosynthesis [61]. Recently, the combination of anti-inflammatory and chemotherapeutic activities for the treatment of cancer has attracted increasing attention [62]. Pathak et al. [63] used the nonsteroidal anti-inflammatory drug (NSAID) aspirin and cisplatin to fabricate a $\mathrm{Pt}(\mathrm{IV})$ prodrug, platin-A, for the treatment of PC (Figure 9(15)). Platin-A showed cytotoxicity similar to that of cisplatin with a slightly higher $\mathrm{IC}_{50}$ value than that of an equimolar mixture of cisplatin and aspirin. However, platin-A markedly reduced the expression of COX-2 and the levels of tumor necrosis factor (TNF)- $\alpha$ and interleukin (IL)-6, which were increased in lipopolysaccharide- (LPS-) activated macrophages. Moreover, platin-A promoted the secretion of the anti-inflammatory cytokine IL-10 in LPS-activated macrophages, which was not observed in LPS-activated macrophages treated with cisplatin, aspirin, or an equimolar mixture of both. These results indicated that platin-A exhibited unique anti-inflammatory and antitumor effects. Cheng et al. [64] also reported a Pt (IV) prodrug, which was a fusion of aspirin and cisplatin, based on antineoplastic effects of aspirin. Compared to cisplatin, this $\mathrm{Pt}(\mathrm{IV})$ complex increased the in vitro 

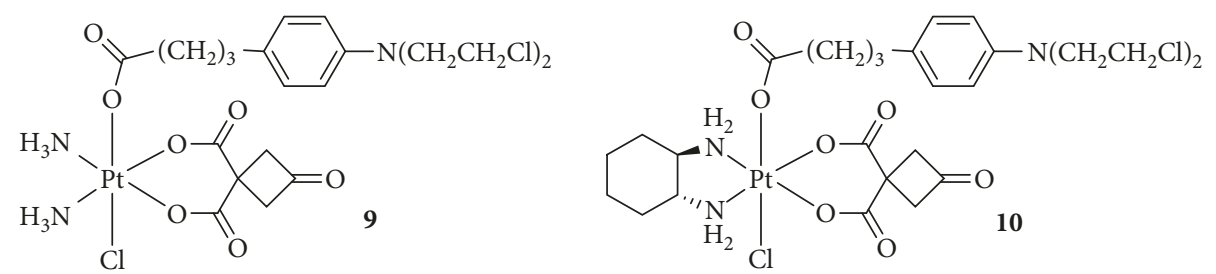

Figure 6: Structure of Pt(IV) prodrugs based on Chl.<smiles>N[PH](N)(O)(Cl)(Cl)OC(=O)c1ccc2c(c1)nc(Nc1cccc(Cl)c1)c1ccncc12</smiles>

11

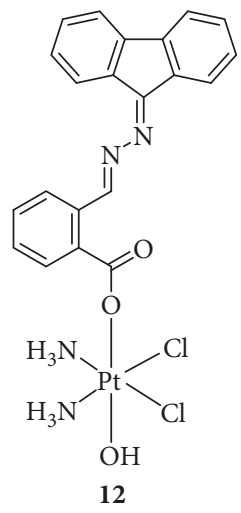

Figure 7: Structure of Pt(IV) prodrugs based on casein kinase 2 (CK2) and nucleotide excision repair (NER) inhibitors.

cytotoxicity by approximately 10 -fold and inhibited the tumor growth in vivo with a low systemic toxicity. Another $\mathrm{Pt}(\mathrm{IV})$ complex conjugated with an NSAID was reported by researchers from Gou's laboratory [65], who used cisplatin, biotin, and indomethacin to synthesize a biotin-Pt(IV)indomethacin hybrid for cancer therapy (Figure 9(16)). This complex effectively targeted cancer cells owing to the presence of the biotin moiety, which was recognized by the biotin receptor overexpressed on the cell surface. In cells, the $\mathrm{Pt}(\mathrm{IV})$ complex was reduced to a DNA-binding $\mathrm{Pt}(\mathrm{II})$ complex, while the released indomethacin inhibited COX activity and modulated the cellular response to the platinum drug. In addition, the biotin-Pt(IV)-indomethacin complex decreased tumor invasiveness and destroyed capillary-like tube formation [66].

In addition, Gou's group $[67,68]$ also synthesized a series of novel $\mathrm{Pt}(\mathrm{IV})$ complexes with wogonin or a wogonin derivative conjugated at an axial position (Figure 9(17-19)). Wogonin, isolated from the root of the medicinal herb Scutellaria baicalensis Georgi, displays anti-inflammatory, antioxidant, and anticancer activities both in vitro and in vivo. The $\mathrm{Pt}(\mathrm{IV})$ complexes obtained inhibited the activity of COX-2 by blocking the CK2-mediated nuclear factor- (NF-) $\kappa \mathrm{B}$ pathway, which promotes tumor survival and invasion. The $\mathrm{Pt}(\mathrm{IV})$ complexes conjugated with the wogonin derivative were multitargeting anticancer agents, owing to the diverse biological activities of wogonin.

2.6. Targeting Mitochondria. The mitochondria occupy $15-50 \%$ of the cytoplasmic volume in most cells and play key roles in cellular energy-generating processes and are considered main regulators of cell survival. Mitochondrial

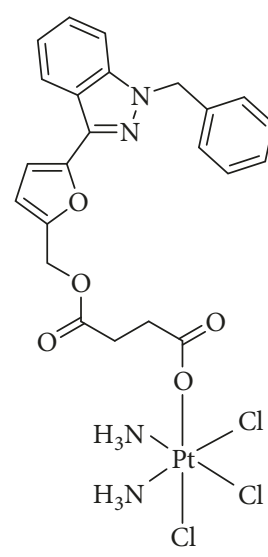

13<smiles>NP(N)(O)(Cl)C(=O)CCC(=O)OCc1ccc(-c2nn(Cc3ccccc3)c3ccccc23)o1</smiles>

14
Figure 8: Structures of Pt(IV) prodrugs YCC-1 and YCC-2.

oxidative phosphorylation provides energy needs for normal cells, whereas cancer cells mainly rely on aerobic glycolysis (the Warburg effect) [69]. This unique glucose metabolic pathway of cancer suggests that the mitochondria could be a prime target for cancer therapy. Dhar and Lippard [70] presented a $\mathrm{Pt}(\mathrm{IV})$ prodrug, mitaplatin (Figure 10(20)), a potent fusion of cisplatin and the orphan drug dichloroacetate (DCA), and explored its bioactivity. DCA, as an anticancer agent without any deleterious effect on normal cells, reversed the Warburg effect [71, 72] by inhibiting pyruvate dehydrogenase kinase (PDK), which is required for this process, which opened the mitochondrial transition pores. This effect released proapoptotic mediators such as cytochrome $c$ and induced the translocation of apoptosisinducing factor (AIF) to induce apoptosis. Mitaplatin displayed a dual killing activity against cancer cells, which included DNA damage by cisplatin and selective mitochondrial damage by DCA in cancer cells. Mitaplatin not only showed high cytotoxicity against tested cancer cells but also decreased the mitochondrial membrane potential gradient, thus, inducing apoptosis by promoting the release and translocation of cytochrome $\mathrm{c}$ and AIF.

However, Zajac and colleagues [73] have demonstrated that mitaplatin, with a half-life of less than $1 \mathrm{~h}$, is not stable in the cell culture medium for the entire period required for in vitro cytotoxicity studies $(24,48$, or $72 \mathrm{~h})$. Thus, the observed biological effects were due to the action of a mixture of mitaplatin and its hydrolysis products. Therefore, researchers designed a new Pt(IV) complex based on DCA and oxaliplatin. The antitumor model was similar to that of the conjugation of cisplatin and DCA, while 5-fluorouracil in 
<smiles>COc1ccc2c(c1)c(CC(=O)OP(N)(N)(Cl)(Cl)(Cl)OC(=O)CCCCC1SCC3NC(=O)NC31)c(C)n2C(=O)c1ccc(Cl)cc1</smiles><smiles>[X]C(I)(I)OC(=O)CCC(=O)OCCCOc1cc(O)c2c(=O)cc(-c3ccccc3)oc2c1OC</smiles>

$17 \mathrm{~L}=\mathrm{H}_{3} \mathrm{~N} \mathrm{X}=\mathrm{Cl}$

$18 \mathrm{~L}, \mathrm{~L}=\mathrm{DACH} X=\mathrm{Cl}$

$19 \mathrm{~L}, \mathrm{~L}=\mathrm{DACH} \mathrm{X}, \mathrm{X}=$ Oxalate

FIgURE 9: Structures of Pt(IV) prodrugs based on aspirin, biotin, and wogonin derivatives.<smiles>NP(Cl)(Cl)(OC(=O)C(Cl)Cl)OC(=O)C(Cl)Cl</smiles><smiles>O=C1O[P](N[C@H]2[C@H](Cl)CCCC[C@H]2OC(=O)C(Cl)Cl)(OC(=O)C(Cl)Cl)OC1=O</smiles><smiles>CCOP(N)(N)(Cl)OC(=O)CCC(=O)Oc1ccc2c(c1)CCC(C)(CCCC(C)CCCC(C)CCCC(C)C)O2</smiles>

FIgUre 10: Structure of Pt(IV) prodrugs based on dichloroacetate (DCA) and vitamin E analog.

combination with DCA-containing Pt(IV) derivatives of oxaliplatin enhanced the antitumor effect (Figure 10(21)).

In addition, Suntharalingam et al. [74] have reported the synthesis of $\mathrm{Pt}(\mathrm{IV})$ complexes conjugated with a vitamin $\mathrm{E}$ analog, $\alpha$-tocopherol succinate (Figure 10(22)), which disrupted mitochondrial function by inhibiting B-cell lymphoma- (BCL-) extra-large (BCL-xL) and BCL-2 proteins. These two proteins are important components of the mitochondrial apoptosis pathway [75]. The results showed that the cytotoxicity was improved 7-220-fold, and the expression of BCL-xL and BCL-2 was decreased by the Pt (IV) prodrugs, suggesting that the dual targeting strategy could be a valuable route for increasing the anticancer efficacy.

Recently, Chen and colleagues [76] developed five new Pt (IV) prodrugs based on cisplatin, carboplatin, oxaliplatin, and their derivatives conjugated with lonidamine (LND) as an axial ligand, which is known to interfere with cancer metabolism by targeting the glycolytic pathway (Figure 11(23-27)). The results showed that all these complexes enhanced antitumor effects against different tumors, especially the Pt(IV) prodrug based on cisplatin, which exhibited significantly improved anticancer activities against LNCaP that was nearly twice as high as that of cisplatin and showed considerably more potential than the physical mixture of cisplatin and LND. Further research showed that this complex was easily reduced by ascorbic acid to release LND at room temperature and triggered cancer cell death via an apoptotic pathway, but with a low cellular uptake of platinum, suggesting that the induction of apoptosis in LNCaP cells was closely associated with mitochondrial function disruption and ROS accumulation, which was associated with LND release.
In summary, these results provide evidence to support the design strategy of conjugating platinum complexes with mitochondria-targeting inhibitors to improve their anticancer effect.

2.7. Targeting Microtubules. Microtubules, composed of $\alpha, \beta$-tubulin heterodimers and well known as a major part of the cytoskeleton, play an important role in many critical cellular processes such as cell signaling, mitotic spindle assembly during cell division, intracellular transport, cell proliferation, and migration $[77,78]$. Inhibition of the assembly of tubulin into microtubules or depolymerization of microtubules leads to apoptosis via arrest of cell division, rendering microtubules an attractive molecular target for antitumor agents [79]. It has been reported that combining cytotoxic, DNA-damaging platinum-based drugs with tubulin inhibitors increases antiproliferative activities. Wang and colleagues $[80,81]$ designed a series of $\mathrm{Pt}(\mathrm{IV})$ complexes comprising the tubulin inhibitor combretastatin A-4 or phenstatin analogs as part of dual-targeting $\mathrm{Pt}(\mathrm{IV})$ prodrugs derived from cisplatin, oxaliplatin, and dichloro(1,2diaminocyclohexane)platinum(II) (Figure 12(28-31)). These $\mathrm{Pt}(\mathrm{IV})$ complexes, conjugated with tubulin inhibitors, showed a good cytotoxicity for cancer cells, including those with cisplatin resistance. Moreover, the complexes effectively accumulated in cells, strongly inhibited tubulin polymerization, blocked the cell cycle at the G2/M phase, and markedly induced cell apoptosis through the mitochondrial pathway. In NCI-H460 and HepG2 xenograft mouse models, although these complexes also inhibited the tumor growth in vivo, the activity was slightly less than that of 


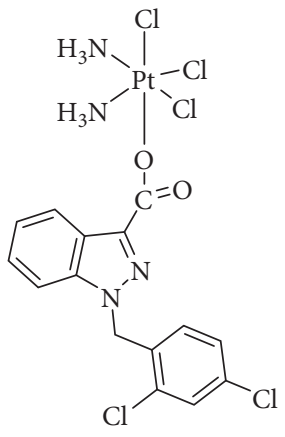

23<smiles>NP1(Cl)(Cl)OC(=O)C2(CCC2)C(=O)O1</smiles>

24<smiles></smiles>

25

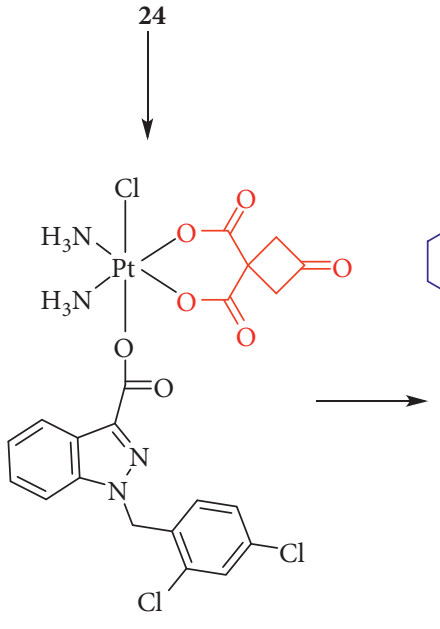

26<smiles></smiles><smiles>CC(=O)c1nn(Cc2ccc(Cl)cc2Cl)c2ccccc12</smiles>

27

Figure 11: Structure of Pt(IV) prodrugs based on lonidamine (LND).

cisplatin. Therefore, they also designed and synthesized a series of new $\mathrm{Pt}(\mathrm{IV})$ prodrugs with millepachine analogs (Figure 12(32-40)), which have been found to exhibit potent inhibitory effects on tubulin polymerization by binding to the colchicine site of tubulin [82]. These compounds are expected not only to carry the DNA damaging platinumbased agent warhead into the tumor cells but also have a millepachine derivative that inhibits tubulin polymerization. Furthermore, in vivo tests showed that this kind of compound effectively inhibited tumor growth without obvious body weight loss in an SK-OV-3 xenograft model in contrast to the reference drugs Pt(II) agents and millepachine. In general, the combination of millepachine analogs $\mathrm{Pt}(\mathrm{II})$ agents is a useful strategy to inhibit tumor growth with low toxicity.

2.8. Targeting Vascular Processes. Angiogenesis promotes tumor growth and is involved in cancer cell development, including survival and metastasis [83]. This process requires the formation of new vessels [84]. Cancer cells promote angiogenesis early in tumorigenesis, which is driven by an oncogene to express proangiogenic proteins such as the vascular endothelial growth factor (VEGF), basic fibroblast growth factor (bFGF), IL-8, placenta-like growth factor (PLGF), and transforming growth factor- (TGF-) $\beta$. [85]. Targeting vascular endothelial cells and blocking tumor angiogenesis is a relatively new approach to cancer therapy.
Mukhopadhyay and colleagues [86] used peptides containing Arg-Gly-Asp (RGD) and Asn-Gly-Arg (NGR, Figure 13(41)), which were added to an axial position to form a series of $\mathrm{Pt}$ (IV)-peptide complexes for targeting the angiogenic tumor vasculature. RGD and NGR can be recognized by integrins $\alpha_{\mathrm{v}} \beta_{3}$ and $\alpha_{\mathrm{v}} \beta_{5}$ and the membrane-spanning surface protein aminopeptidase $N$, respectively, which are highly expressed in tumor-induced angiogenesis [87]. The RGD- and NGRtethered Pt(IV) complexes showed better inhibition of cellular proliferation than nonspecific Pt(IV)-peptide analogs, suggesting selective transport of platinum anticancer agents into tumor endothelial cells. Lana [88] also synthesized four antivascular trans-Pt(II)/(IV) complexes with acetylpyridine as a ligand (Figure 13(42-45)). These complexes exhibited antiangiogenesis effects, whereas the Pt(II) complexes were more effective than the $\mathrm{Pt}(\mathrm{IV})$ complexes.

It is worth mentioning that Yang et al. [89] reported two phosphaplatins, a $\mathrm{Pt}(\mathrm{IV})$ drug without a bioactive ligand (1R,2R-diaminocyclohexane)(dihydropyrophosphato) (transdihydroxo) Pt(IV) (RRD4, Figure 13(47)) and a Pt(II) drug (RRD2, Figure 13(46)), targeting VEGF receptor (VEGFR-2 instead of DNA). These phosphaplatins markedly inhibited both cell migration and tube formation in vitro and tumor vascularization in vivo, and moreover, the activities of RRD2 were better than that of RRD4, whereas cisplatin and carboplatin did not. The researchers proposed that the mechanism of phosphaplatin's antiangiogenic activity was that the sulfur-containing protein side chains of 
<smiles>COc1ccc(/C=C\c2ccc(OC)c(OCC(=O)OP(N)(N)(Cl)Cl)c2)cc1OC</smiles>

28<smiles>COc1ccc(C(=O)c2cc(OC)c(OC)c(OC)c2)cc1OCC(=O)OP(N)(N)(Cl)Cl</smiles>

$\mathrm{Cl} 29$<smiles>COc1ccc(C(=O)c2cc(OC)c(OC)c(OC)c2)cc1OCC(=O)OP([NH3+])(Cl)(Cl)N[C@@H]1CCCC[C@H]1N</smiles>

30<smiles>COc1ccc(C(=O)c2cc(OC)c(OC)c(OC)c2)cc1OCC(=O)OP1(N)(N[C@@H]2CCCC[C@H]2N)OC(=O)C(=O)O1</smiles>

31<smiles>COc1ccc(/C=C/C(=O)c2ccc(OC)c3c2OC(C)(C)C=C3)cc1NC(=O)NC(=O)OP(N)(N)(Cl)C(C)(Cl)Cl</smiles><smiles>COc1cccc2c1C=CC(C)C2</smiles><smiles>C=CC(C(=O)/C=C/c1ccc(OC)c(NC(=O)C(C)=O)c1)=C(C)OC(C)(C)C</smiles>
$34 \mathrm{n}=3$

$40 \mathrm{n}=6 \mathrm{O}=\mathrm{O}_{\mathrm{Cl}}^{\mathrm{Pt}} \underset{\mathrm{H}_{2}}{\mathrm{~N}^{\prime \prime \prime}}$

$40 \mathrm{n}=6$ O $\mathrm{O}_{\mathrm{Cl}}^{\mathrm{n}=4} \mathrm{H}_{2}$ $36 \mathrm{n}=4$ $39 \mathrm{n}=6$ $\mathrm{Cl} \mathrm{H}_{2}$

FIgURE 12: Structure of Pt(IV) prodrugs based on combretastatin A-4, phenstatin analogs, and millepachine analogs.<smiles>[X]C(=O)CCC(=O)OP(N)(N)(Cl)Cl</smiles>

$\mathrm{X}=\mathrm{RGD}, \mathrm{NGR}, \mathrm{AGR}, \mathrm{Gly}$ , $(\mathrm{CRGDC})_{\mathrm{c}} \mathrm{X}=(\mathrm{RGDfK})_{\mathrm{c}}{ }^{\mathrm{b}}$

41<smiles></smiles><smiles>CC(=O)c1ccc[n+](C(Cl)(Cl)[Te](Cl)(Cl)(Cl)(Cl)Cl)c1</smiles><smiles></smiles>

44

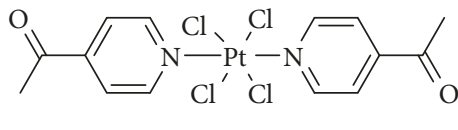

45<smiles>[N]C1(N)OP(=O)(O)OP(=O)(O)O1</smiles>

46<smiles></smiles>

47

Figure 13: Structure of Pt(IV) prodrugs based on Arg-Gly-Asp (RGD), Asn-Gly-Arg (NGR), and acetylpyridine.

VEGFR-2 may form metal-ligand complexes with phosphaplatins through displacement of the $\mathrm{Pt}$ pyrophosphate ligand. Unfortunately, phosphaplatins are not susceptible to aquation at $\mathrm{pH} 7.4$, and greater solution stability may play a major role in determining their ultimate biological targets.
2.9. Targeting GSH-S-Transferase. Drug resistance is one of the most serious factors limiting clinical applications of cisplatin, which is involved in multifactorial processes. GSHS-transferase (GST) enzymes have been demonstrated to be the most important factors of drug resistance. They are well 
known to catalyze the conjugation of GSH to cisplatin in cells to detoxify cisplatin, resulting in drug resistance $[88,90]$. Studies have shown that GST enzymes are overexpressed in various cisplatin-resistant cells, especially pi class GST (GSTP1-1), an important enzyme in the mercapturic acid detoxification pathway. The inhibition of GST activity could reverse drug resistance. It has been reported that a GST inhibitor (ethacrynic acid, EA) combined with alkylating agents (Chl and thiotepa) for the treatment of tumor showed some success [91]. Therefore, researchers used Pt(IV) compounds conjugated to EA to overcome the GST-mediated drug resistance (Figure 14(48)). The Pt(IV)-EA complexes not only strongly inhibited the GST activity in cell-free and cell systems ( $\sim$ 10-fold of EA alone) but also rapidly kill cancer cells. To understand the molecular mechanism, Parker and colleagues [92] investigated the drug-protein interactions between $\mathrm{Pt}(\mathrm{IV})$ EA and GST P1-1, supported by molecular modeling analysis using quantum mechanical/molecular mechanical methods. The results showed that EA-CPT preferentially docks at the dimer interface at GST P1-1 and subsequent interaction with the enzyme resulted in docking of the ethacrynate ligands at both active sites (in the $\mathrm{H}$-sites), with the Pt moiety remaining bound at the dimer interface. The activation of the inhibitor by its target enzyme and covalent binding accounts for the strong and irreversible inhibition of enzymatic activity by the platinum complex. Interestingly, Zanellato et al. [93] found that Pt (IV and II)-ethacrynic acid conjugates showed poorer performance than the reference drug cisplatin alone or in combination with EA did in the treatment of MPM, and cellular GST activity remained consistently unchanged. This may be related to the type of cancer.

However, the Pt(IV)-EA conjugate containing a cDDP core and two axial ethacrynate ligands did not readily release a Pt(II) species to exert a synergistic cytotoxic effect and had poor aqueous solubility. To overcome these shortcomings, Lee et al. [94] redesigned a new Pt(IV) construct comprising a CDDP core with one axial ethacrynate ligand and one axial hydroxido ligand (Figure 14(49)). This compound was not only more soluble in the phosphate buffer at the required concentrations, due to the substitution of the hydrophobic ethacrynate ligand with the hydrophilic hydroxide moiety, but also more susceptible to reduction. Moreover, the novel complex not only remained the inhibitory activity of GST but also obviously reduced tumor growth in vivo in a chicken embryo with low toxicities compared with cisplatin, thus validating the new design strategy.

2.10. Targeting Glutamine (Gln) Receptor. Glutamine (Gln), a nonessential amino acid, is abundant in the plasma, reaching $0.4-0.7 \mathrm{mM}$ concentrations [95]. Gln plays an important role in the rapid growth of the tumor by providing nitrogen and carbon for the biosynthesis of components such as nucleotides and hexosamines [96]. Interestingly, in some cancer cells such as pancreatic, glioblastoma, leukemia, lung, and breast cancers, Gln deprivation induced cell apoptosis, which is known as "Gln addiction." Based on this observation, targeting Gln addiction is an attractive strategy for cancer therapy. Ravera et al. [97] synthesized a small series of Gln- or
Gln derivative-conjugated Pt(IV) complexes (Figure 15(5054)). Unfortunately, these complexes were less potent than cisplatin, while showing decreased off-target accumulation. Therefore, new amino acid-conjugated $\mathrm{Pt}(\mathrm{IV})$ complexes need to be designed for targeting tumor cells.

2.11. Targeting Immunoregulation. Because toxic drugs are considered immunosuppressive, the use of chemotherapy that targets the immune system was discounted [98]. In fact, clinical data have shown that platinum agents directly or indirectly act as immune effectors. Nonetheless, this fact has been ignored in the development of new therapeutics, and studies have primarily focused on targeting DNA. Presently, attractive immunotherapy approaches mainly include chimeric antigen receptor (CAR) T-cell therapies, cancer vaccines, dendritic cell therapies, and immune checkpoint inhibitors [99, 100]. The common inhibitory immune checkpoints include programmed cell death protein 1 (PD-1), cytotoxic T-lymphocyte-associated protein 4 (CTLA-4), T-cell immunoglobulin and mucin-domain containing-3 (TIM3), and indoleamine 2,3-dioxygenase (IDO) [101]. Targeted immune checkpoint therapy could increase the antitumor immune response by affecting $\mathrm{T}$ cells. Taking advantage of the potential synergy between platinum drugs and immune checkpoint inhibitors by developing combination therapies is likely to provide survival benefits to patients. Awuah et al. [102] adopted the Pt(IV) prodrug strategy to combine the immunomodulator (D)-1-MT (IDO inhibitor) with cisplatin to obtain the first immuno-chemotherapeutic agent for DNA cross-linking-induced apoptosis (Figure 16(55 and 56)). This complex effectively induced DNA damage, blocked IDO to prevent T-cell degradation, and downregulated the aryl hydrocarbon receptor (AHR) and IL-6, which are key genes involved in the autoregulation of constitutive IDO expression, resulting in T-cell proliferation. Wong et al. [103] synthesized an immuno-chemotherapeutic $\mathrm{Pt}(\mathrm{IV})$ prodrug using a formyl peptide receptor (FPR) $1 / 2$ peptide combined with cisplatin (Figure 16(57-61)). The results showed that the FPR1/2 peptide not only efficiently delivered cisplatin to cancer cells, which overexpressed FPR1/2 on the surface, but also activated, as a potent immune adjuvant, an immune anticancer response. Therefore, combining chemotherapy with immunotherapy to achieve a therapeutic synergy is a feasible approach.

2.12. Multitargeting. In general, "dual-action" $\mathrm{Pt}(\mathrm{IV})$ prodrugs are designed to treat cancers based on the combination of a single chemotherapeutic entity with a single bioactive entity. Recently, Petruzzella and colleagues [104] created a "quadruple-action" $\mathrm{Pt}(\mathrm{IV})$ prodrug that released four different bioactive moieties, cisplatin, DCA (PDK inhibitor), $\mathrm{PhB}$ (HDAC inhibitor), and Pt56MeSS, in KRAS-mutated cancer cells (Figure 17(62 and 63)). The data showed that this $\mathrm{Pt}(\mathrm{IV})$ prodrug significantly increased the cytotoxicity, 200-450-fold compared with that of cisplatin, in KRASmutated pancreatic and colon cancers, which resulted from synergism between DNA platination, HDAC inhibition, and action on the mitochondria. Compared to normal cells, the 
<smiles>C=C(CC)C(=O)c1ccc(OCC(=O)OP(N)(N)(Cl)OC(=O)COc2ccc(C(=O)C(=C)CC)c(Cl)c2Cl)c(Cl)c1Cl</smiles>

48<smiles>C=C(CC)C(=O)c1ccc(OCC(=O)O[P+](N)(N)Cl)c(Cl)c1Cl</smiles>

49

FIgURe 14: Structure of Pt(IV) prodrugs based on ethacrynic acid (EA).<smiles>CC(=O)OP(N)(N)(Cl)OC(=O)CCNC(=O)C(N)CCC(N)=O</smiles>

50<smiles>CCCCC(=O)NCCC(=O)OP(N)(N)(Cl)OC(C)=O</smiles>

51<smiles></smiles>

53<smiles></smiles>

54

Figure 15: Structure of Pt(IV) prodrugs based on glutamine (Gln).<smiles>Cn1cc(CC(N)C(=O)OP(C)(N)(Cl)OC(=O)[C@@H](N)Cc2cn(C)c3ccccc23)c2ccccc21</smiles><smiles>CCCCCCCCCCCCCCCCNC(=O)OP(N)(N)(Cl)OC(=O)CCC(=O)NCCOC(=O)[C@H](N)Cc1cn(C)c2ccccc12</smiles><smiles>CCNC(=O)CON=Cc1ccc(C(=O)OP(N)(N)(Cl)(Cl)(Cl)OC(C)=O)cc1</smiles>

55

FIgURE 16: Structure of Pt(IV) prodrugs based on (D)-1-MT and formyl peptide receptor 1 and 2 (FPR1/2) peptide.

recognition capability of this $\mathrm{Pt}(\mathrm{IV})$ prodrug for cancer cells was 40 -fold higher. The study provides a novel option for using Pt(IV)-based "quadruple-action" prodrugs as anticancer agents.

\subsection{Targeting Cell-Surface Receptors}

2.13.1. Targeting Estrogen Receptor (ER) and Androgen Receptor (AR). Barnes et al. [105] demonstrated that estrogen receptor- (ER-) positive cancer cells are sensitized to cisplatin by treatment with estrogen, which could shield cisplatin-DNA adducts from NER through overexpression of the high-mobility group box 1 (HMGB1) protein. HMGB1 is the most abundant and prominent member of the HMG family of ubiquitous and highly conserved nonhistone chromosomal proteins found in higher eukaryotes [106]. It has been reported that the level of chromosomal architectural protein HMGB1 is upregulated by estrogen and steroid hormones [107]. Importantly, HMGB1 binds specifically to the major cisplatin-DNA adducts, 1,2-intrastrand d (GpG) and $\mathrm{d}(\mathrm{ApG})$ cross-links, which comprise $90 \%$ of the lesions, inhibiting repair of DNA damage by the NER and sensitizing cancer cells to cisplatin [108]. Therefore, the authors designed a series of $\mathrm{Pt}(\mathrm{IV})$ derivatives conjugated to estrogen, called bis-estrogen-cis-diamminedichloroplatinum
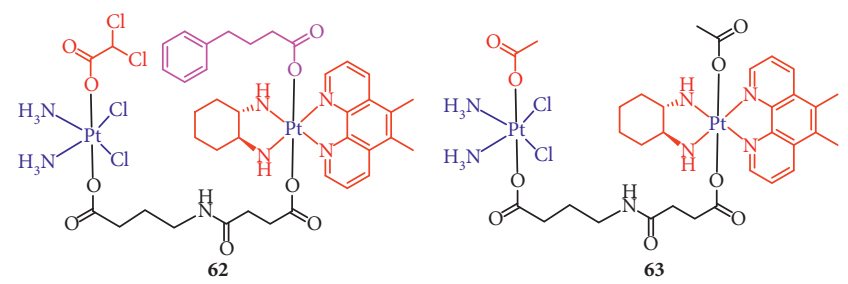

Figure 17: Structure of $\mathrm{Pt}(\mathrm{IV})$ prodrugs based on cisplatin, dichloroacetate (DCA), 4-phenylbutyric acid (PhB), and Pt56MeSS.

(IV) $\left(\mathrm{BEP}_{\mathrm{n}}\right.$, Figure 18(64)). The results showed that all $\mathrm{BEP}_{\mathrm{n}}$ complexes induced overexpression of HMGB1 in ER ${ }^{+} \mathrm{MCF}-7$ cells compared with $\mathrm{ER}^{-}$HCC-1937 cells, and BEP3 was nearly 2-fold more cytotoxic to $\mathrm{ER}^{+} \mathrm{MCF}-7$ cells than it was to $\mathrm{ER}^{-}$HCC-1937 cells. These observations suggest that these complexes specifically to target $\mathrm{ER}^{+}$cancer cells such as breast and ovarian cancer cells provide a direct strategy to enhance the antitumor effect of platinum complexes. In addition, Gou's group [109] reported conjugation of the Pt(IV) moiety to the ER modulator tamoxifen, named Tam-Pt(IV) (Figure 18(65-68)), which was selectively and efficiently taken up by $\mathrm{ER}^{+}$positive tumor cells. In $\mathrm{ER}^{+}$positive tumor cells, these $\mathrm{Pt}(\mathrm{IV})$ complexes could be activated by intracellular reducing molecules such as 

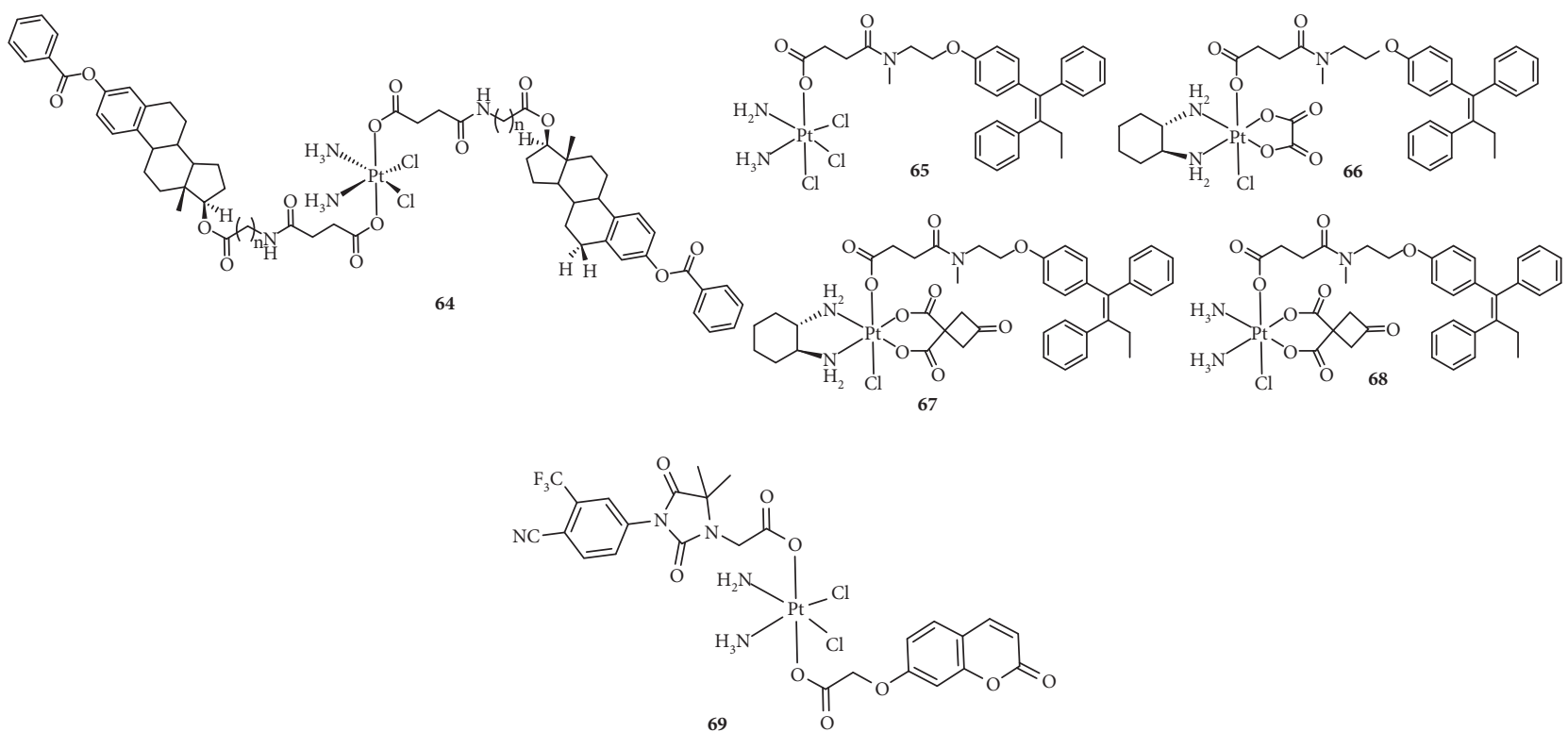

FIGURE 18: Structure of Pt(IV) prodrugs based on estrogen, tamoxifen, and androgen receptor (AR).

ascorbic acid and GSH to release the Pt(II) complex and tamoxifen moieties simultaneously and regain their pharmacological activity. Tamoxifen, as a first-line endocrine therapy, has been widely used for patients with all stages of $\mathrm{ER}^{+}$breast cancer; however, its use has been limited by intrinsic and acquired drug resistance. However, these Tam-Pt(IV) compounds were found to reverse the tamoxifen resistance of breast cancer, particularly that of MCF-7 (ER $\alpha^{+}$breast cancer cells), but it was less effective toward MDA-MB-231 (ER $\alpha$ negative breast cancer cells). Therefore, the combination of estrogen modulators and the platinum moiety could enhance selective development of platinum in $\mathrm{ER}^{+}$tumors and possibly expand the clinical scope of the ER ligand in resistant breast tumors.

Currently, PC is one of the leading causes of cancer-related deaths in men worldwide, especially castration-resistant PC (CRPC), with poor prognosis, metastatic spreading, and a median survival range from 18 to 24 months. Although the mechanisms responsible for the progression of PC to CRPC are not well known, the expression level of the AR is reported to be approximately 6-fold higher in CRPC than hormonesensitive PC, suggesting that AR protein is essential for CRPC to adapt to the low levels of androgens in PC. Therefore, Qin and colleagues [110] reported a Pt(IV)-based prodrug targeting AR (Figure 18(69)). This compound was found to display satisfactory AR binding affinity and selectively accumulated in LNCaP (AR+) cells, other than PC-3 (AR-) cells, which could be effectively visualized. Moreover, it exhibited excellent anticancer activity superior to that of cisplatin.

\subsubsection{Targeting Membrane-Bound Heat Shock Protein 70} (memHSP70). Heat shock protein 70 (HSP70), a stressinducible chaperone, is overexpressed in many cancers including colorectal cancer. Clinical data has shown that $50 \%$ of patient tumors were characterized by obvious overexpression of a membrane-bound form of HSP70 (memHSP70) [111]. Normal cells maintain memHSP70 homeostasis, while in tumor cells, the expression of memHSP70 is upregulated, which is associated with cancer progression and poor prognosis. Gehrmann et al. [111] reported that TPP, an HSP70-derived 14-mer peptide, could rapidly bind to an epitope in the oligomerization domain of HSP70 and be taken up by internalization, suggesting that TPP may have the potential to target cancer cells that express HSP70. Based on this hypothesis, McKeon et al. [112] combined oxaliplatin with TPP to synthesize a novel Pt(IV) prodrug. This complex targeted cancer cells through specific binding and internalization by memHSP $70^{+}$tumor cells.

2.13.3. Targeting Glucose Transporters. Carbohydrates play important roles in various biological processes and can significantly promote the unrestricted proliferation of cancer cells. Carbohydrate uptake mainly involves two types of proteins: glucose transporters (GLUTs) and sodiumdependent glucose transporters (SGLTs), which are overexpressed in tumor cells because of the Warburg effect and are prognostic indicators for cancer, especially GLUT1 $[113,114]$. Therefore, the combination of a sugar and antitumor agents has become an attractive strategy for cancer therapy. It has been reported that novel glycosylated Pt(II) agents showed obviously reduced toxicity and enhanced antitumor activity. Recently, several glycosylated Pt(IV) prodrugs have been synthesized and explored for their bioactivity [115-117]. These glycosylated Pt(IV) complexes (Figure 19(70-73)), with various sugars (glucose, mannose, galactose, or rhamnose) conjugated to a platinum core (cisplatin or oxaliplatin), were found to be comparable or even superior to cisplatin or oxaliplatin. The $\mathrm{IC}_{50}$ and cytoplasmic concentrations of glycosylated Pt(IV) complexes varied depending on the axial ligand, Pt core, or cell phenotype. In general, Pt(IV) complexes with the cisplatin core were more effective than their oxaliplatin counterparts, and mannose, galactose, or rhamnose were more potent than glucose. Moreover, Ma et al. 


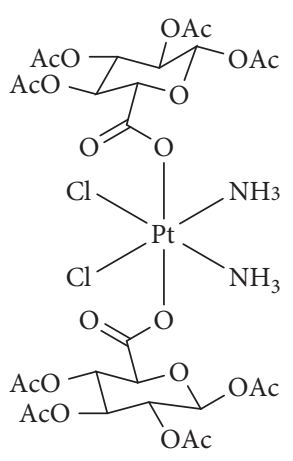

70

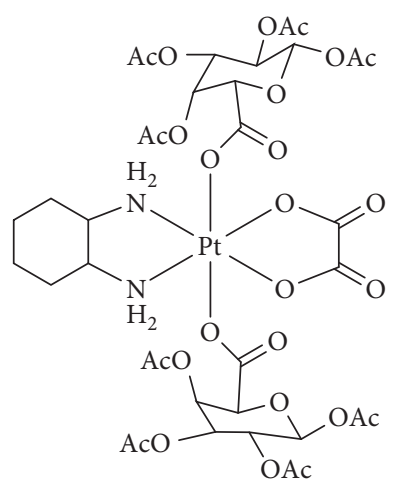

71

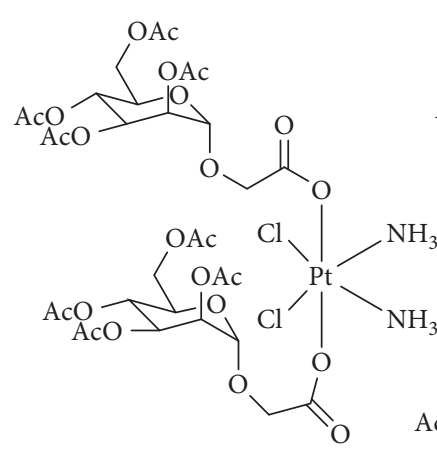

72

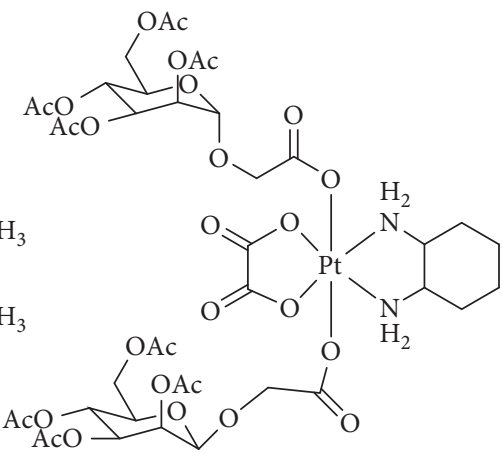

73

FIGURE 19: Structure of glycosylated Pt(IV) prodrugs.

[116] evaluated the effects of glycosylated Pt(IV) complexes on GLUT1. The results showed that these complexes were GLUT and organic cation transporter (OCT) substrates and contributed greatly to targeted therapy, although it had been previously reported that $\mathrm{Pt}(\mathrm{IV})$ complexes protected by acetyl groups did not have such properties. The precise mechanism needs to be further studied.

\subsubsection{Targeting Chlorotoxin (CTX) Receptors.} Chlorotoxin (CTX, TM601) [118], a 36-amino-acid peptide with four disulfide bridges, was extracted from the venom of the giant yellow Israeli scorpion Leiurus quinquestriatus hebraeus. It has been reported that CTX binds to matrix metalloproteinase 2 (MMP2) or chloride ion channels. In general, the level of MMP2 increases, and chloride ion channels are overexpressed in cancers [119]. In addition, the annexin A2 protein has also been reported as a receptor for CTX [120]. These proteins are attractive targets for the development of targeted drugs. Graf et al. [121] have used CTX as a carrier for cisplatin and synthesized Pt(IV)-CTX conjugates for targeting cancer cells (Figure 20(74)). The results showed an increased efficacy of the platinum complex in three different cell lines compared to that of CTX or Pt (IV); however, the efficacy was lower than that of cisplatin.

2.13.5. Targeting Integrins. Among the receptors overexpressed on tumor cells, integrins are attractive pharmacological targets. They are transmembrane cell adhesion glycoproteins involved in the migration, invasion, proliferation, and survival of tumor cells [122]. In particular, $\alpha_{\mathrm{V}} \beta_{3}$ and $\alpha_{\mathrm{V}} \beta_{5}$ integrins are frequently overexpressed in tumor endothelial cells in the lung, breast, melanoma, prostate, ovarian carcinoma, and brain tumors. Studies have shown that RGD is efficiently recognized by $\alpha_{\mathrm{V}} \beta_{3}$ and $\alpha_{\mathrm{V}} \beta_{5}$ integrins [123]. Therefore, using the high affinity of RGD to $\alpha_{\mathrm{V}} \beta_{3}$ and $\alpha_{\mathrm{V}} \beta_{5}$ integrins, researchers [124-127] synthesized some $\mathrm{Pt}(\mathrm{IV})$ prodrugs based on RGD-containing peptides or peptidomimetics to deliver platinum drugs to cancer cells or for tumor imaging (Figure 21(75 and 76)). These complexes effectively targeted and massively accumulated in cancer cells to induce tumor cell death with low toxicity to normal

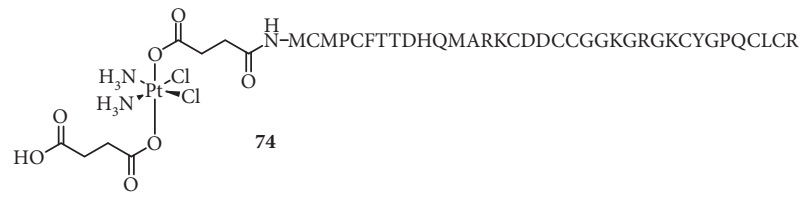

Figure 20: Structure of $\mathrm{Pt}(\mathrm{IV})$ prodrugs based on chlorotoxin (CTX).

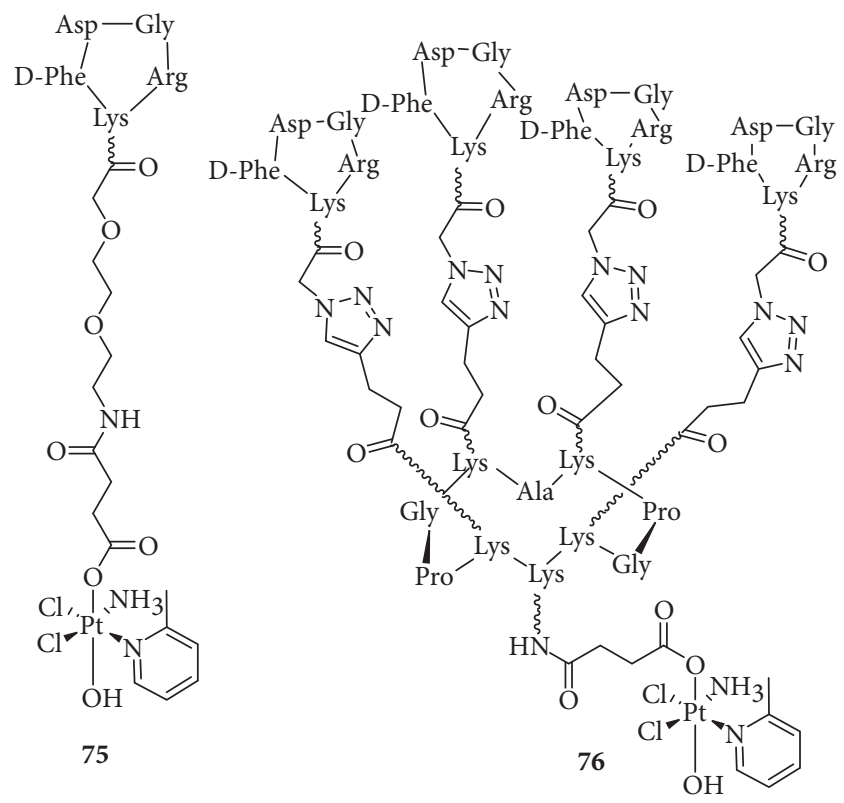

FIgure 21: Structure of Pt-c(RGDfk) and Pt-RAFT-\{c(RGDfk) 4 .

cells. In these complexes, RGD mainly serves as a carrier for drug delivery.

\section{Conclusions}

Although cisplatin is widely used in cancer treatment, its drawbacks such as acquired resistance limits its clinical applications and has led to the development of novel drugs with improved properties. To overcome the shortcomings of cisplatin, one approach is the development of $\mathrm{Pt}(\mathrm{IV})$ 
prodrugs with two axial ligands, which exhibit inertness before entering cells and minimize unwanted interactions with nucleophiles in the serum, thus reducing side effects and enhancing bioavailability. In recent years, multiple Pt (IV) prodrugs have been synthesized through modification of the two axial ligands to improve or confer particular features such as hydrophobicity, targeted delivery, photosensitivity, reduction quality, and dual or multiple functions. This review summarized the recent progress in the development of $\mathrm{Pt}(\mathrm{IV})$ prodrugs conjugated with biologically active ligands. Although such prodrugs were synthesized to exert dual function, these complexes frequently displayed multiple functions. Thus, Pt(IV) complexes conjugated with HDAC inhibitors not only affect DNA and HDAC activities but also influence related apoptosis pathways such as the mitochondrial pathway. The regulation of intracellular signals involves a vast network, but Pt(IV) prodrugs conjugated with biologically active ligands could, to some extent, increase accumulation in target tissue and antitumor activity, reduce toxicity, and overcome drug resistance. Therefore, Pt(IV) prodrugs conjugated with bioactive ligands are still considered a promising strategy for cancer therapy.

\section{Conflicts of Interest}

The authors declare that there are no conflicts of interest regarding the publication of this article.

\section{Authors' Contributions}

Xuejiao Li and Yahong Liu contributed equally to this work.

\section{Acknowledgments}

This work was supported by the innovation team funding (1649) from the Institute of Radiation Medicine, Chinese Academy of Medical Sciences (CAMS), and Peking Union Medical College (PUMC), the Fundamental Research Fund for CAMS and PUMC (2016ZX310199), the CAMS Innovation Fund for Medical Science (CIFMS, 2017-I2M-3019) from the CAMS and PUM, and Tianjin Major Scientific and Technological Special Project for Significant New Drug Developments (17ZXXYSY00090).

\section{References}

[1] B. Rosenberg, L. Vancamp, and T. Krigas, "Inhibition of cell division in Escherichia coli by electrolysis products from a platinum electrode," Nature, vol. 205, no. 4972, pp. 698-699, 1965.

[2] F. M. Muggia, A. Bonetti, J. D. Hoeschele, M. Rozencweig, and S. B. Howell, "Platinum antitumor complexes: 50 years since Barnett Rosenberg's discovery," Journal of Clinical Oncology, vol. 33, no. 35, pp. 4219-4226, 2015.

[3] E. Cvitkovic and M. Bekradda, "Oxaliplatin: a new therapeutic option in colorectal cancer," Seminars in Oncology, vol. 26, no. 6, pp. 647-662, 1999.

[4] P. J. O’Dwyer, J. P. Stevenson, and S. W. Jonson, "Clinical pharmacokinetics and administration of established platinum drugs," Drugs, vol. 59, no. 4, pp. 19-27, 2000.
[5] B. Rosenberg, L. Vancamp, J. E. Trosko, and V. H. Mansour, "Platinum compounds: a new class of potent antitumour agents," Nature, vol. 222, pp. 385-386, 1969.

[6] N. J. Wheate, S. Walker, G. E. Craig, and R. Oun, "The status of platinum anticancer drugs in the clinic and in clinical trials," Dalton Transactions, vol. 39, no. 35, p. 8113, 2010.

[7] D. Gibson, "Platinum(iv) anticancer prodrugs-hypotheses and facts," Dalton Transactions, vol. 45, no. 33, pp. $12983-$ 12991, 2016.

[8] J. Reedijk, "The mechanism of action of platinum antitumor drugs," Pure and Applied Chemistry, vol. 59, no. 2, pp. 181-192, 1987.

[9] L. Galluzzi, I. Vitale, J. Michels et al., "Systems biology of cisplatin resistance: past, present and future," Cell Death \& Disease, vol. 5, no. 5, p. e1257, 2014.

[10] K. S. Lovejoy and S. J. Lippard, "Non-traditional platinum compounds for improved accumulation, oral bioavailability, and tumor targeting," Dalton Transactions, vol. 38, no. 48, pp. 10651-10659, 2009.

[11] M. Galanski, M. A. Jakupec, and B. K. Keppler, "Update of the preclinical situation of anticancer platinum complexes: novel design strategies and innovative analytical approaches," Current Medicinal Chemistry, vol. 12, no. 18, pp. 2075-2094, 2005.

[12] A. Najjar, N. Rajabi, and R. Karaman, "Recent approaches to platinum(IV) prodrugs: a variety of strategies for enhanced delivery and efficacy," Current Pharmaceutical Design, vol. 23, no. 16, pp. 2366-2376, 2017.

[13] M. R. Reithofer, A. K. Bytzek, S. M. Valiahdi et al., "Tuning of lipophilicity and cytotoxic potency by structural variation of anticancer platinum(IV) complexes," Journal of Inorganic Biochemistry, vol. 105, no. 1, pp. 46-51, 2011.

[14] F. Zák, J. Turánek, A. Kroutil et al., "Platinum(IV) complex with adamantylamine as nonleaving amine group: synthesis, characterization, and in vitro antitumor activity against a panel of cisplatin-resistant cancer cell lines," Journal of Medicinal Chemistry, vol. 47, no. 3, pp. 761-763, 2004.

[15] T. C. Johnstone, K. Suntharalingam, and S. J. Lippard, "The next generation of platinum drugs: targeted $\mathrm{Pt}(\mathrm{II})$ agents, nanoparticle delivery, and Pt(IV) prodrugs," Chemical Reviews, vol. 116, no. 5, pp. 3436-3486, 2016.

[16] P. J. Bednarski, K. Korpis, A. F. Westendorf, S. Perfahl, and R. Grunert, "Effects of light-activated diazido-Pt(IV) complexes on cancer cells in vitro," Philosophical Transactions of the Royal Society A: Mathematical, Physical and Engineering Sciences, vol. 371, no. 1995, article 20120118, 2013.

[17] E. Gabano, M. Ravera, and D. Osella, "Pros and cons of bifunctional platinum(IV) antitumor prodrugs: two are (not always) better than one," Dalton Transactions, vol. 43, no. 26, pp. 9813-9820, 2014.

[18] T. Kouzarides, "Chromatin modifications and their function," Cell, vol. 128, no. 4, pp. 693-705, 2007.

[19] T. Groh, J. Hrabeta, M. A. Khalil, H. Doktorova, T. Eckschlager, and M. Stiborova, "The synergistic effects of DNA-damaging drugs cisplatin and etoposide with a histone deacetylase inhibitor valproate in high-risk neuroblastoma cells," International Journal of Oncology, vol. 47, no. 1, pp. 343-352, 2015.

[20] V. Santini, A. Gozzini, and G. Ferrari, "Histone deacetylase inhibitors: molecular and biological activity as a premise to clinical application," Current Drug Metabolism, vol. 8, no. 4, pp. 383-393, 2007.

[21] L. Peng, Z. Yuan, and E. Seto, Histone Deacetylase Activity Assay, Vol. 1288, Springer Nature, Basel, Switzerland, 2015. 
[22] A. Atmaca, S. E. Al-Batran, A. Maurer et al., "Valproic acid (VPA) in patients with refractory advanced cancer: a dose escalating phase I clinical trial," British Journal of Cancer, vol. 97, no. 2, pp. 177-182, 2007.

[23] P. Munster, D. Marchion, E. Bicaku et al., "Clinical and biological effects of valproic acid as a histone deacetylase inhibitor on tumor and surrogate tissues: phase I/II trial of valproic acid and epirubicin/FEC," Clinical Cancer Research, vol. 15, no. 7, pp. 2488-2496, 2009.

[24] A. Rocca, S. Minucci, G. Tosti et al., "A phase I-II study of the histone deacetylase inhibitor valproic acid plus chemoimmunotherapy in patients with advanced melanoma," British Journal of Cancer, vol. 100, no. 1, pp. 28-36, 2009.

[25] F. Vandermeers, P. Hubert, P. Delvenne et al., "Valproate, in combination with pemetrexed and cisplatin, provides additional efficacy to the treatment of malignant mesothelioma," Clinical Cancer Research, vol. 15, no. 8, pp. 2818-2828, 2009.

[26] J. Sonnemann, J. Gange, S. Pilz et al., "Comparative evaluation of the treatment efficacy of suberoylanilide hydroxamic acid (SAHA) and paclitaxel in ovarian cancer cell lines and primary ovarian cancer cells from patients," BMC Cancer, vol. 6 , no. 1, p. 183, 2006.

[27] H. Tatebe, M. Shimizu, Y. Shirakami et al., "Acyclic retinoid synergises with valproic acid to inhibit growth in human hepatocellular carcinoma cells," Cancer Letters, vol. 285, no. 2, pp. 210-217, 2009.

[28] K. L. Jin, J. Y. Park, E. J. Noh et al., “The effect of combined treatment with cisplatin and histone deacetylase inhibitors on HeLa cells," Journal of Gynecologic Oncology, vol. 21, no. 4, pp. 262-268, 2010.

[29] J. Yang, X. Sun, W. Mao, M. Sui, J. Tang, and Y. Shen, "Conjugate of $\mathrm{Pt}(\mathrm{IV})$-histone deacetylase inhibitor as a prodrug for cancer chemotherapy," Molecular Pharmaceutics, vol. 9, no. 10, pp. 2793-2800, 2012.

[30] N. Takai, N. Kawamata, D. Gui, J. W. Said, I. Miyakawa, and H. P. Koeffler, "Human ovarian carcinoma cells: histone deacetylase inhibitors exhibit antiproliferative activity and potently induce apoptosis," Cancer, vol. 101, no. 12, pp. 2760-2770, 2004.

[31] M. Alessio, I. Zanellato, I. Bonarrigo, E. Gabano, M. Ravera, and D. Osella, "Antiproliferative activity of $\mathrm{Pt}(\mathrm{IV})$-bis (carboxylato) conjugates on malignant pleural mesothelioma cells," Journal of Inorganic Biochemistry, vol. 129, pp. 52-57, 2013.

[32] H. L. Kindler, "Systemic treatments for mesothelioma: standard and novel," Current Treatment Options in Oncology, vol. 9, no. 2-3, pp. 171-179, 2008.

[33] V. Novohradsky, L. Zerzankova, J. Stepankova et al., "New insights into the molecular and epigenetic effects of antitumor Pt(IV)-valproic acid conjugates in human ovarian cancer cells," Biochemical Pharmacology, vol. 95, no. 3, pp. 133-144, 2015.

[34] V. Novohradsky, L. Zerzankova, J. Stepankova et al., “Antitumor platinum(IV) derivatives of oxaliplatin with axial valproato ligands," Journal of Inorganic Biochemistry, vol. 140, pp. 72-79, 2014.

[35] R. Raveendran, J. P. Braude, E. Wexselblatt et al., "Pt(iv) derivatives of cisplatin and oxaliplatin with phenylbutyrate axial ligands are potent cytotoxic agents that act by several mechanisms of action," Chemical Science, vol. 7, no. 3, pp. 2381-2391, 2016.

[36] A. R. Z. Almotairy, V. Gandin, L. Morrison, C. Marzano, D. Montagner, and A. Erxleben, "Antitumor platinum(IV) derivatives of carboplatin and the histone deacetylase inhibitor 4-phenylbutyric acid," Journal of Inorganic Biochemistry, vol. 177, pp. 1-7, 2017.

[37] B. W. J. Harper, E. Petruzzella, R. Sirota et al., "Synthesis, characterization and in vitro and in vivo anticancer activity of $\mathrm{Pt}(\mathrm{iv})$ derivatives of [Pt(1S,2S-DACH) (5,6-dimethyl-1,10phenanthroline)]," Dalton Transactions, vol. 46, no. 21, pp. 7005-7019, 2017

[38] D. Griffith, M. P. Morgan, and C. J. Marmion, "A novel anticancer bifunctional platinum drug candidate with dual DNA binding and histone deacetylase inhibitory activity," Chemical Communications, no. 44, pp. 6735-6737, 2009.

[39] L. Ning, D. Y. Greenblatt, M. Kunnimalaiyaan, and H. Chen, "Suberoyl bis-hydroxamic acid activates notch-1 signaling and induces apoptosis in medullary thyroid carcinoma cells," Oncologist, vol. 13, no. 2, pp. 98-104, 2008.

[40] B. R. You and W. H. Park, "Suberoyl bishydroxamic acidinduced apoptosis in HeLa cells via ROS-independent, GSHdependent manner," Molecular Biology Reports, vol. 40, no. 5, pp. 3807-3816, 2013.

[41] J. Kasparkova, H. Kostrhunova, O. Novakova et al., “A photoactivatable platinum(IV) complex targeting genomic DNA and histone deacetylases," Angewandte Chemie International Edition, vol. 54, no. 48, pp. 14478-14482, 2015.

[42] C. A. Finlay, P. W. Hinds, and A. J. Levine, "The p53 protooncogene can act as a suppressor of transformation," Cell, vol. 57, no. 7, pp. 1083-1093, 1989.

[43] J. Chen, "The cell-cycle arrest and apoptotic functions of p53 in tumor initiation and progression," Cold Spring Harbor Perspectives in Medicine, vol. 6, no. 3, p. a026104, 2016.

[44] T. Soussi, "The p53 tumor suppressor gene: from molecular biology to clinical investigation," Annals of the New York Academy of Sciences, vol. 910, no. 1, pp. 121-139, 2006.

[45] S. Shangary and S. Wang, "Small-molecule inhibitors of the MDM2-p53 protein-protein interaction to reactivate p53 function: a novel approach for cancer therapy," Annual Review of Pharmacology and Toxicology, vol. 49, no. 1, pp. 223-241, 2009.

[46] S. K. Kumar, E. Hager, C. Pettit, H. Gurulingappa, N. E. Davidson, and S. R. Khan, "Design, synthesis, and evaluation of novel boronic-chalcone derivatives as antitumor agents," Journal of Medicinal Chemistry, vol. 46, no. 14, pp. 2813-2815, 2003.

[47] L. Ma, Y. Wang, X. Zhu et al., "Chalcoplatin, a dual-targeting and p53 activator containing anticancer platinum(IV) prodrug with unique mode of action," Chemical Communications, vol. 51, no. 29, pp. 6301-6304, 2015.

[48] W H Organization, The Selection and Use of Essential Medicines, WHO Model List of Essential Medicines, WHO, Geneva, Switzerland, 2014.

[49] A. A. Nazarov, S. M. Meier, O. Zava et al., "Protein ruthenation and DNA alkylation: chlorambucilfunctionalized RAPTA complexes and their anticancer activity," Dalton Transactions, vol. 44, no. 8, pp. 3614-3623, 2015.

[50] G. B. Faguet, "Chronic lymphocytic leukemia: an updated review," Journal of Clinical Oncology, vol. 12, no. 9, pp. 1974-1990, 1994.

[51] M. Millard, J. D. Gallagher, B. Z. Olenyuk, and N. Neamati, "A selective mitochondrial-targeted chlorambucil with remarkable cytotoxicity in breast and pancreatic cancers," Journal of Medicinal Chemistry, vol. 56, no. 22, pp. 91709179, 2013. 
[52] M. Di Antonio, K. I. McLuckie, and S. Balasubramanian, "Reprogramming the mechanism of action of chlorambucil by coupling to a G-quadruplex ligand," Journal of the American Chemical Society, vol. 136, no. 16, pp. 5860-5863, 2014.

[53] F. Chen, G. Xu, X. Qin, X. Jin, and S. Gou, "Hybrid of DNAtargeting chlorambucil with $\mathrm{Pt}(\mathrm{IV})$ species to reverse drug resistance," Journal of Pharmacology and Experimental Therapeutics, vol. 363, no. 2, pp. 221-239, 2017.

[54] X. Qin, L. Fang, F. Chen, and S. Gou, "Conjugation of platinum(IV) complexes with chlorambucil to overcome cisplatin resistance via a "joint action" mode toward DNA," European Journal of Medicinal Chemistry, vol. 137, pp. 167-175, 2017.

[55] F. Chen, X. Huang, M. Wu, S. Gou, and W. Hu, "A CK2targeted $\mathrm{Pt}(\mathrm{IV})$ prodrug to disrupt DNA damage response," Cancer Letters, vol. 385, pp. 168-178, 2017.

[56] Z. Wang, Z. Xu, and G. Zhu, "A platinum(IV) anticancer prodrug targeting nucleotide excision repair to overcome cisplatin resistance," Angewandte Chemie International Edition, vol. 55, no. 50, pp. 15564-15568, 2016.

[57] W. R. Wilson and M. P. Hay, "Targeting hypoxia in cancer therapy," Nature Reviews Cancer, vol. 11, no. 6, pp. 393-410, 2011.

[58] W. Lv, Z. Zhang, K. Y. Zhang et al., "A mitochondriatargeted photosensitizer showing improved photodynamic therapy effects under hypoxia," Angewandte Chemie International Edition, vol. 55, no. 34, pp. 9947-9951, 2016.

[59] Z. Xu, J. Zhao, S. Gou, and G. Xu, "Novel hypoxia-targeting Pt(IV) prodrugs," Chemical Communications, vol. 53, no. 26, pp. 3749-3752, 2017.

[60] A. M. D. Marzo, E. A. Platz, S. Sutcliffe et al., "Inflammation in prostate carcinogenesis," Nature Reviews Cancer, vol. 7, no. 4, pp. 256-269, 2007.

[61] T. Hussain, S. Gupta, and H. Mukhtar, "Cyclooxygenase-2 and prostate carcinogenesis," Cancer Letters, vol. 191, no. 2, pp. 125-135, 2003.

[62] C. Lin and J. Zhang, "Inflammasomes in inflammationinduced cancer," Frontiers in Immunology, vol. 8, p. 271, 2017.

[63] R. K. Pathak, S. Marrache, J. H. Choi, T. B. Berding, and S. Dhar, "The prodrug platin-A: simultaneous release of cisplatin and aspirin," Angewandte Chemie International Edition, vol. 53, no. 7, pp. 1963-1967, 2014.

[64] Q. Cheng, H. Shi, H. Wang, Y. Min, J. Wang, and Y. Liu, "The ligation of aspirin to cisplatin demonstrates significant synergistic effects on tumor cells," Chemical Communications, vol. 50, no. 56, pp. 7427-7430, 2014.

[65] W. Hu, L. Fang, W. Hua, and S. Gou, "Biotin-Pt (IV)indomethacin hybrid: a targeting anticancer prodrug providing enhanced cancer cellular uptake and reversing cisplatin resistance," Journal of Inorganic Biochemistry, vol. 175, pp. 47-57, 2017.

[66] J. Zhao, W. Hua, G. Xu, and S. Gou, "Biotinylated platinum (IV) complexes designed to target cancer cells," Journal of Inorganic Biochemistry, vol. 176, pp. 175-180, 2017.

[67] X. Qin, G. Xu, F. Chen, L. Fang, and S. Gou, "Novel platinum (IV) complexes conjugated with a wogonin derivative as multi-targeted anticancer agents," Bioorganic \& Medicinal Chemistry, vol. 25, no. 8, pp. 2507-2517, 2017.

[68] F. Chen, X. Qin, G. Xu, S. Gou, and X. Jin, "Reversal of cisplatin resistance in human gastric cancer cells by a wogonin-conjugated $\mathrm{Pt}(\mathrm{IV})$ prodrug via attenuating casein kinase 2-mediated nuclear factor-KB pathways," Biochemical Pharmacology, vol. 135, pp. 50-68, 2017.

[69] G. B. Stefano and R. M. Kream, "Cancer: mitochondrial origins,” Medical Science Monitor, vol. 21, pp. 3736-3739, 2015.

[70] S. Dhar and S. J. Lippard, "Mitaplatin, a potent fusion of cisplatin and the orphan drug dichloroacetate," Proceedings of the National Academy of Sciences, vol. 106, no. 52, pp. 22199-22204, 2009.

[71] P. W. Stacpoole, N. V. Nagaraja, and A. D. Hutson, "Efficacy of dichloroacetate as a lactate-lowering drug," Journal of Clinical Pharmacology, vol. 43, no. 7, pp. 683-691, 2003.

[72] S. Bonnet, S. L. Archer, J. Allalunis-Turner et al., "A mitochondria-K channel axis is suppressed in cancer and its normalization promotes apoptosis and inhibits cancer growth," Cancer Cell, vol. 11, no. 1, pp. 37-51, 2007.

[73] J. Zajac, H. Kostrhunova, V. Novohradsky et al., "Potentiation of mitochondrial dysfunction in tumor cells by conjugates of metabolic modulator dichloroacetate with a Pt(IV) derivative of oxaliplatin," Journal of Inorganic Biochemistry, vol. 156, pp. 89-97, 2016.

[74] K. Suntharalingam, Y. Song, and S. J. Lippard, "Conjugation of vitamin $\mathrm{E}$ analog $\alpha$-TOS to Pt(IV) complexes for dualtargeting anticancer therapy," Chemical Communications, vol. 50, no. 19, pp. 2465-2468, 2014.

[75] C. W. Shiau, J. W. Huang, D. S. Wang et al., " $\alpha$-Tocopheryl succinate induces apoptosis in prostate cancer cells in part through inhibition of Bcl-xL/Bcl-2 function," Journal of Biological Chemistry, vol. 281, no. 17, pp. 11819-11825, 2006.

[76] H. Chen, F. Chen, W. Hu, and S. Gou, "Effective platinum (IV) prodrugs conjugated with lonidamine as a functional group working on the mitochondria," Journal of Inorganic Biochemistry, vol. 180, pp. 119-128, 2018.

[77] S. Etienne-Manneville, "From signaling pathways to microtubule dynamics: the key players," Current Opinion in Cell Biology, vol. 22, no. 1, pp. 104-111, 2010.

[78] M. Kavallaris, "Microtubules and resistance to tubulinbinding agents," Nature Reviews Cancer, vol. 10, no. 3, pp. 194-204, 2010.

[79] J. R. McIntosh, E. L. Grishchuk, and R. R. West, "Chromosome-microtubule interactions during mitosis," Annual Review of Cell and Developmental Biology, vol. 18, no. 1, pp. 193-219, 2002.

[80] X. Huang, R. Huang, S. Gou, Z. Wang, Z. Liao, and H. Wang, "Platinum(IV) complexes conjugated with phenstatin analogue as inhibitors of microtubule polymerization and reverser of multidrug resistance," Bioorganic \& Medicinal Chemistry, vol. 25, no. 17, pp. 4686-4700, 2017.

[81] X. Huang, R. Huang, S. Gou, Z. Wang, Z. Liao, and H. Wang, "Combretastatin A-4 analogue: a dual-targeting and tubulin inhibitor containing antitumor Pt(IV) moiety with a unique mode of action," Bioconjugate Chemistry, vol. 27, no. 9, pp. 2132-2148, 2016.

[82] X. Huang, S. Hua, R. Huang et al., "Dual-targeting antitumor hybrids derived from Pt(IV) species and millepachine analogues," European Journal of Medicinal Chemistry, vol. 148, pp. 1-25, 2018.

[83] R. Kerbel and J. Folkman, "Clinical translation of angiogenesis inhibitors," Nature Reviews Cancer, vol. 2, no. 10, pp. 727-739, 2002.

[84] E. Ruoslahti, "RGD and other recognition sequences for integrins," Annual Review of Cell and Developmental Biology, vol. 12, no. 1, pp. 697-715, 1996. 
[85] J. M. Healy, O. Murayama, T. Maeda, K. Yoshino, K. Sekiguchi, and M. Kikuchi, "Peptide ligands for integrin $\alpha \mathrm{v} \beta 3$ selected from random phage display libraries," Biochemistry, vol. 34, no. 12, pp. 3948-3955, 1995.

[86] S. Mukhopadhyay, A. Haskel, S. M. Short, K. R. Barnes, S. J. Lippard, and C. M. Barnés, "Conjugated platinum(IV)peptide complexes for targeting angiogenic tumor vasculature," Bioconjugate Chemistry, vol. 19, no. 1, pp. 39-49, 2008.

[87] M. Aumailley, M. Gurrath, G. Muller, J. Calvete, R. Timpl, and H. Kessler, "Arg-Gly-Asp constrained within cyclic pentapeptides. Strong and selective inhibitors of cell adhesion to vitronectin and laminin fragment P1," FEBS Letters, vol. 291, no. 1, pp. 50-54, 1991.

[88] F. Lana, A. Sandra, K. Ana, J. Radmila, D. Biljana, and R. Siniša, "Trans-platinum(II)/(IV) complexes with acetylpyridine ligands as antivascular agents in vitro: cytotoxic and antiangiogenic potential," Anti-Cancer Agents in Medicinal Chemistry, vol. 16, no. 12, pp. 1628-1639, 2016.

[89] L. Yang, S. Moghaddas, H. Dezvareh et al., "Insights into the anti-angiogenic properties of phosphaplatin," Journal of Inorganic Biochemistry, vol. 164, pp. 5-16, 2016.

[90] G. Ferrandina, G. Scambia, G. Damia et al., "Glutathione S-transferase activity in epithelial ovarian cancer: association with response to chemotherapy and disease outcome," Annals of Oncology, vol. 8, no. 4, pp. 343-350, 1997.

[91] W. H. Ang, I. Khalaila, C. S. Allardyce, L. Juillerat-Jeanneret, and P. J. Dyson, "Rational design of platinum(IV) compounds to overcome glutathione-S-transferase mediated drug resistance," Journal of the American Chemical Society, vol. 127, no. 5, pp. 1382-1383, 2005.

[92] L. J. Parker, L. C. Italiano, C. J. Morton et al., "Studies of glutathione transferase P1-1 bound to a platinum(IV)-based anticancer compound reveal the molecular basis of its activation," Chemistry-A European Journal, vol. 17, no. 28, pp. 7806-7816, 2011.

[93] I. Zanellato, I. Bonarrigo, M. Sardi et al., "Evaluation of platinum-ethacrynic acid conjugates in the treatment of mesothelioma," ChemMedChem, vol. 6, no. 12, pp. 22872293, 2011.

[94] K. G. Z. Lee, M. V. Babak, A. Weiss et al., "Development of an efficient dual-action GST-inhibiting anticancer platinum (IV) prodrug," ChemMedChem, vol. 13, no. 12, pp. 12101217, 2018.

[95] M. Schlemmer, U. Suchner, B. Schapers et al., "Is glutamine deficiency the link between inflammation, malnutrition, and fatigue in cancer patients?," Clinical Nutrition, vol. 34, no. 6, pp. 1258-1265, 2015.

[96] C. Hensley, A. T. Wasti, and R. J. D. Berardinis, "Glutamine and cancer: cell biology, physiology, and clinical opportunities," Journal of Clinical Investigation, vol. 123, no. 9, pp. 3678-3684, 2013.

[97] M. Ravera, E. Gabano, S. Tinello, I. Zanellato, and D. Osella, "May glutamine addiction drive the delivery of antitumor cisplatin-based Pt(IV) prodrugs?," Journal of Inorganic Biochemistry, vol. 167, pp. 27-35, 2017.

[98] R. A. Lake and B. W. Robinson, "Immunotherapy and chemotherapy-a practical partnership," Nature Reviews Cancer, vol. 5, no. 5, pp. 397-405, 2005.

[99] N. A. W. Lemmermann and M. J. Reddehase, "Refining human T-cell immunotherapy of cytomegalovirus disease: a mouse model with 'humanized' antigen presentation as a new preclinical study tool," Medical Microbiology and Immunology, vol. 205, no. 6, pp. 549-561, 2016.
[100] M. S. Kim, J. S. Y. Ma, H. Yun et al., "Redirection of genetically engineered CAR-T cells using bifunctional small molecules," Journal of the American Chemical Society, vol. 137, no. 8, pp. 2832-2835, 2015.

[101] L. P. Kane, "T cell Ig and mucin domain proteins and immunity," Journal of Immunology, vol. 184, no. 6, pp. 27432749, 2010.

[102] S. G. Awuah, Y. R. Zheng, P. M. Bruno, M. T. Hemann, and S. J. Lippard, "A $\mathrm{Pt}(\mathrm{IV})$ pro-drug preferentially targets indoleamine-2,3-dioxygenase, providing enhanced ovarian cancer immuno-chemotherapy," Journal of the American Chemical Society, vol. 137, no. 47, pp. 14854-14857, 2015.

[103] D. Y. Wong, C. H. Yeo, and W. H. Ang, "Immunochemotherapeutic platinum(IV) prodrugs of cisplatin as multimodal anticancer agents," Angewandte Chemie International Edition, vol. 53, no. 26, pp. 6752-6756, 2014.

[104] J. P. B. E. Petruzzella, J. Aldrich-Wright, V. Gandin, D. Gibson, and J. P. Braude, "A quadruple action platinum (IV) prodrug with anticancer activity against KRAS mutated cancer cell lines," Angewandte Chemie International Edition, vol. 56, no. 38, pp. 11539-11544, 2017.

[105] K. R. Barnes, A. Kutikov, and S. J. Lippard, "Synthesis, characterization, and cytotoxicity of a series of estrogentethered platinum(IV) complexes," Chemistry \& Biology, vol. 11, no. 4, pp. 557-564, 2004.

[106] K.Y. Chau, H. Y. P. Lam, and K. L. D. Lee, "Estrogen treatment induces elevated expression of HMG1 in MCF-7 cells," Experimental Cell Research, vol. 241, no. 1, pp. 269272, 1998.

[107] Q. He, C. H. Liang, and S. J. Lippard, "Steroid hormones induce HMG1 overexpression and sensitize breast cancer cells to cisplatin and carboplatin," Proceedings of the National Academy of Sciences, vol. 97, no. 11, pp. 5768-5772, 2000.

[108] J. C. Huang, D. B. Zamble, J. T. Reardon, S. J. Lippard, and A. Sancar, "HMG-domain proteins specifically inhibit the repair of the major DNA adduct of the anticancer drug cisplatin by human excision nuclease," Proceedings of the National Academy of Sciences, vol. 91, no. 22, pp. 1039410398, 1994.

[109] W. Hu, J. Zhao, W. Hua, and S. Gou, "Study on platinum(IV) species containing an estrogen receptor modulator to reverse tamoxifen resistance of breast cancer," Metallomics, vol. 2, pp. 1-3, 2013.

[110] X. Qin, L. Fang, J. Zhao, and S. Gou, "Theranostic Pt(IV) conjugate with target selectivity for androgen receptor," Inorganic Chemistry, vol. 57, no. 9, pp. 5019-5029, 2018.

[111] M. Gehrmann, S. Stangl, G. A. Foulds et al., "Tumor imaging and targeting potential of an Hsp70-derived 14-mer peptide," PLoS One, vol. 9, no. 8, Article ID e105344, 2014.

[112] A. M. McKeon, J. Noonan, M. Devocelle, B. M. Murphy, and D. M. Griffith, "Platinum(IV) oxaliplatin-peptide conjugates targeting memHsp $70^{+}$phenotype in colorectal cancer cells," Chemical Communications, vol. 53, no. 82, pp. 11318-11321, 2017.

[113] M. G. Vander Heiden, L. C. Cantley, and C. B. Thompson, "Understanding the Warburg effect: the metabolic requirements of cell proliferation," Science, vol. 324, no. 5930, pp. 1029-1033, 2009.

[114] L. Szablewski, "Expression of glucose transporters in cancers," Biochimica et Biophysica Acta (BBA)-Reviews on Cancer, vol. 1835, no. 2, pp. 164-169, 2013.

[115] J. Ma, Q. Wang, X. Yang et al., "The glycosylated platinum (IV) prodrugs demonstrated significant therapeutic efficacy 
in cancer cells and minimized side-effects," Dalton Transactions, vol. 45, no. 29, pp. 11830-11838, 2016.

[116] J. Ma, Q. Wang, Z. Huang et al., "Glycosylated platinum(IV) complexes as substrates for glucose transporters (GLUTs) and organic cation transporters (OCTs) exhibited cancer targeting and human serum albumin binding properties for drug delivery," Journal of Medicinal Chemistry, vol. 60, no. 13, pp. 5736-5748, 2017.

[117] J. Ma, X. Yang, W. Hao, Z. Huang, X. Wang, and P. G. Wang, "Mono-functionalized glycosylated platinum(IV) complexes possessed both $\mathrm{pH}$ and redox dual-responsive properties: exhibited enhanced safety and preferentially accumulated in cancer cells in vitro and in vivo," European Journal of $\mathrm{Me}$ dicinal Chemistry, vol. 128, pp. 45-55, 2017.

[118] J. Deshane, C. C. Garner, and H. Sontheimer, "Chlorotoxin inhibits glioma cell invasion via matrix metalloproteinase-2," Journal of Biological Chemistry, vol. 278, no. 6, pp. 41354144, 2003.

[119] L. Soroceanu, T. J. J. Manning, and H. Sontheimer, "Modulation of glioma cell migration and invasion using $\mathrm{Cl}(-)$ and $\mathrm{K}(+)$ ion channel blockers," Journal of Neuroscience, vol. 19, no. 14, pp. 5942-5954, 1999.

[120] K. Kesavan, J. Ratliff, E. W. Johnson et al., "Annexin A2 is a molecular target for TM601, a peptide with tumortargeting and anti-angiogenic effects," Journal of Biological Chemistry, vol. 285, no. 7, pp. 4366-4374, 2010.

[121] N. Graf, T. E. Mokhtari, I. A. Papayannopoulos, and S. J. Lippard, "Platinum(IV)-chlorotoxin (CTX) conjugates for targeting cancer cells," Journal of Inorganic Biochemistry, vol. 110, pp. 58-63, 2012.

[122] J. K. Ko and K. K. Auyeung, "Identification of functional peptides from natural and synthetic products on their anticancer activities by tumor targeting," Current Medicinal Chemistry, vol. 21, no. 21, pp. 2346-2356, 2014.

[123] F. Danhier, A. Le Breton, and V. Preat, "RGD-based strategies to target alpha(v) beta(3) integrin in cancer therapy and diagnosis," Molecular Pharmaceutics, vol. 9, no. 11, pp. 2961-2973, 2012.

[124] A. Massaguer, A. Gonzalez-Canto, E. Escribano et al., "Integrin-targeted delivery into cancer cells of a Pt(IV) prodrug through conjugation to RGD-containing peptides," Dalton Transactions, vol. 44, no. 1, pp. 202-212, 2015.

[125] N. Graf, D. R. Bielenberg, N. Kolishetti et al., " $\alpha_{\mathrm{V}} \beta_{3}$ Integrintargeted PLGA-PEG nanoparticles for enhanced anti-tumor efficacy of a Pt(IV) prodrug," ACS Nano, vol. 6, no. 5, pp. 4530-4539, 2012.

[126] A. C. Conibear, S. Hager, J. Mayr et al., "Multifunctional $\alpha \mathrm{v} \beta 6$ integrin-specific peptide-Pt(IV) conjugates for cancer cell targeting," Bioconjugate Chemistry, vol. 28, no. 9, pp. 2429-2439, 2017.

[127] A. Gandioso, E. Shaili, A. Massaguer et al., "An integrintargeted photoactivatable Pt(IV) complex as a selective anticancer pro-drug: synthesis and photoactivation studies," Chemical Communications, vol. 51, no. 44, pp. 9169-9172, 2015. 

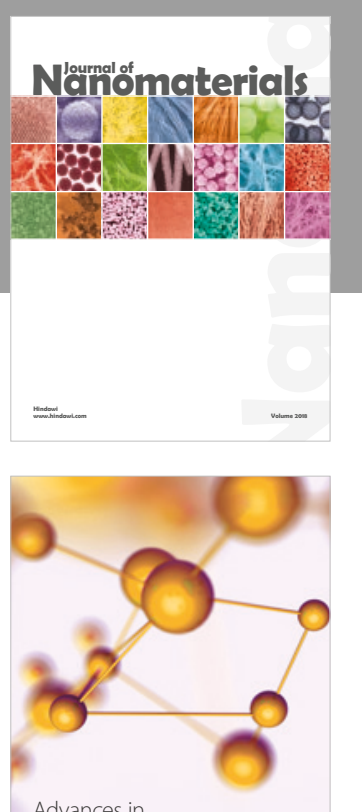

Physical Chemistry
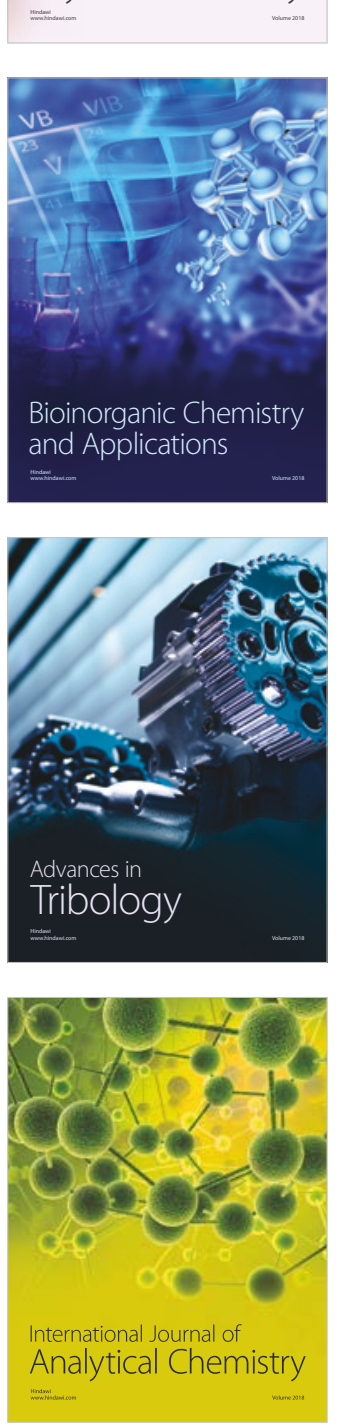

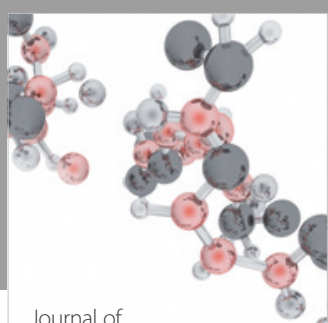

Analytical Methods

in Chemistry

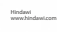

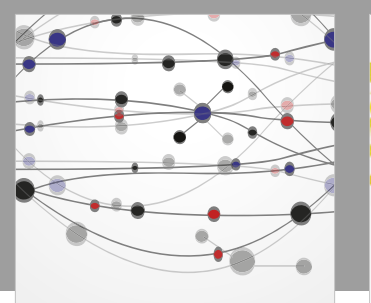

The Scientific World Journal

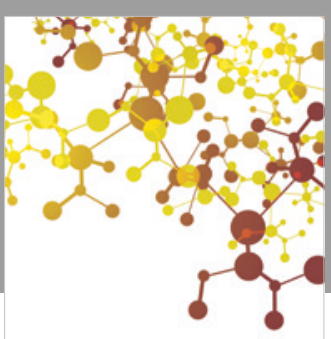

Journal of

Applied Chemistry
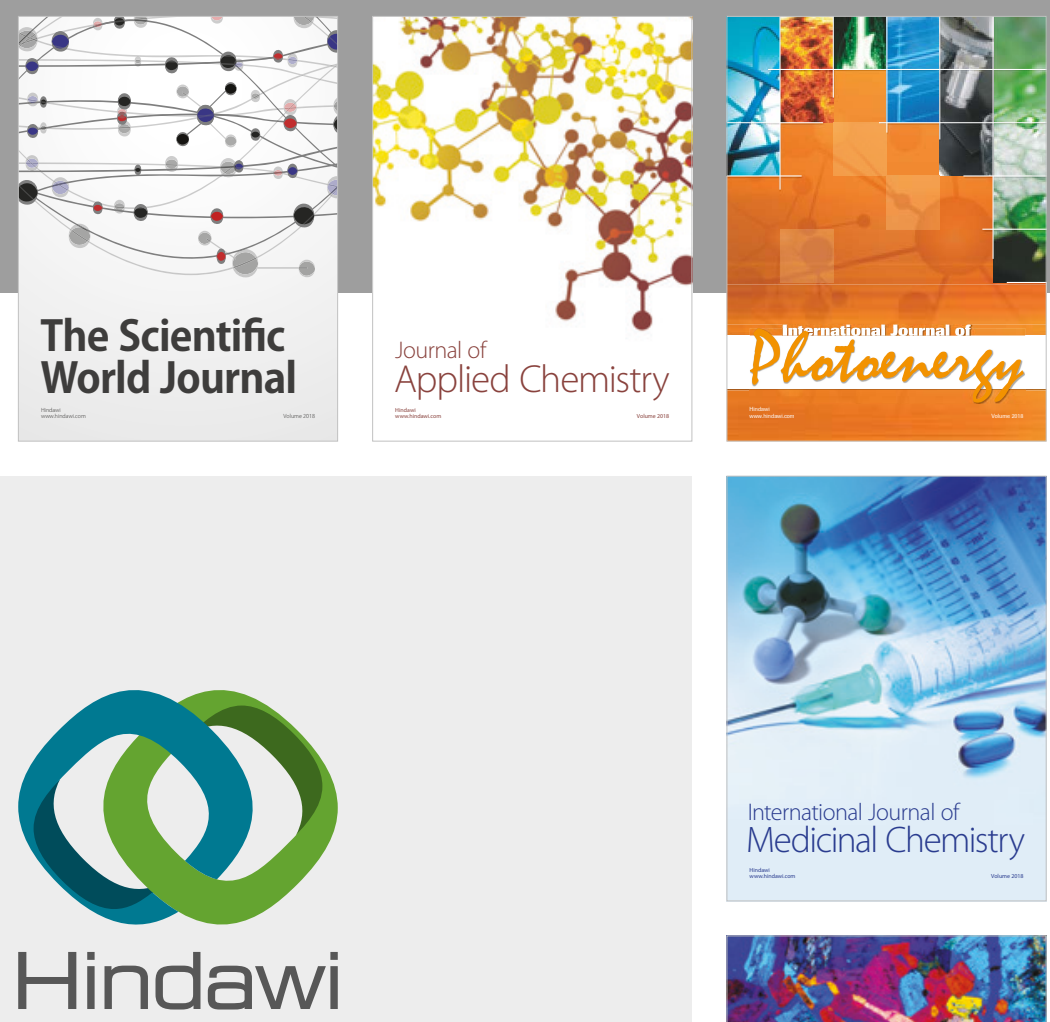

Submit your manuscripts at

www.hindawi.com
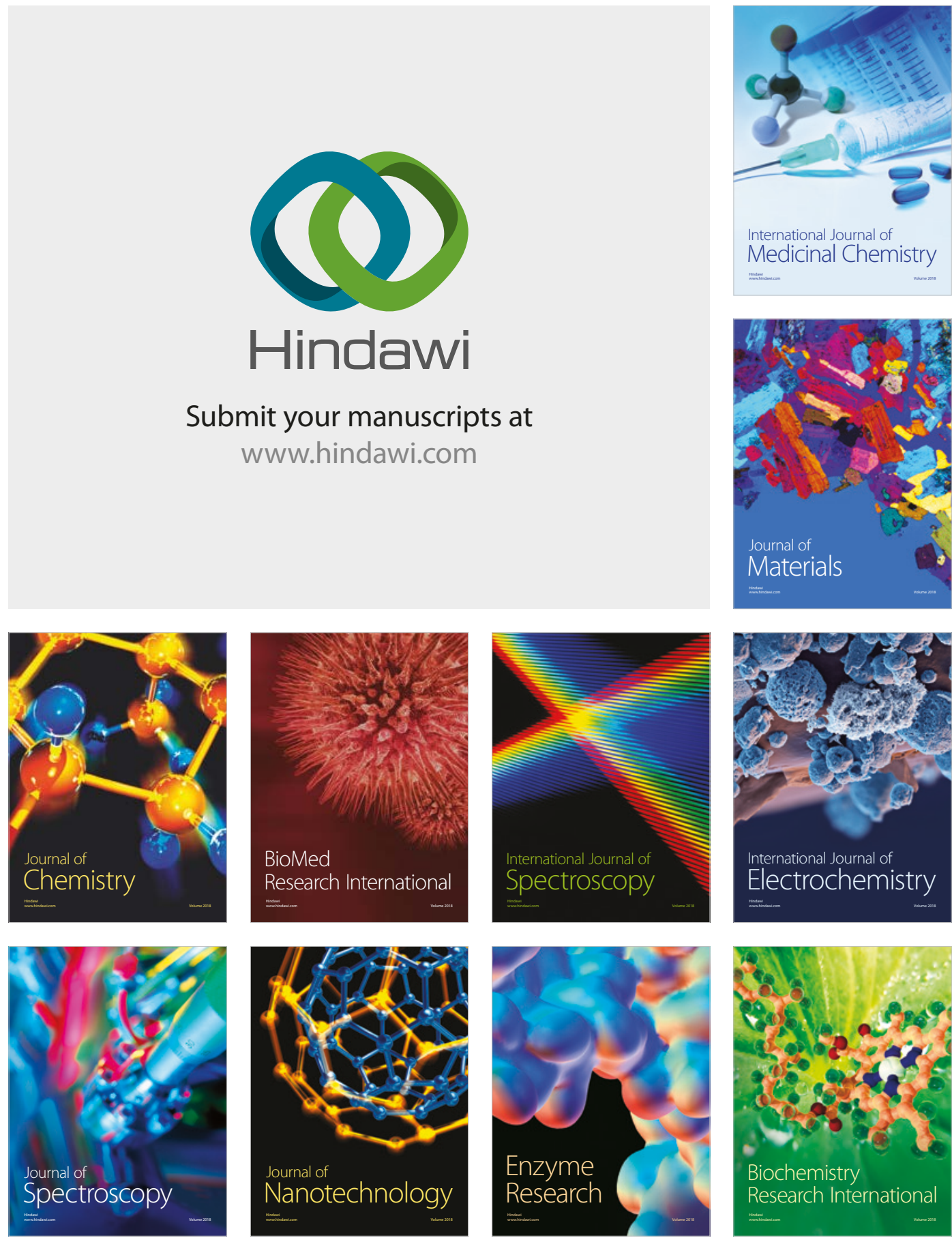
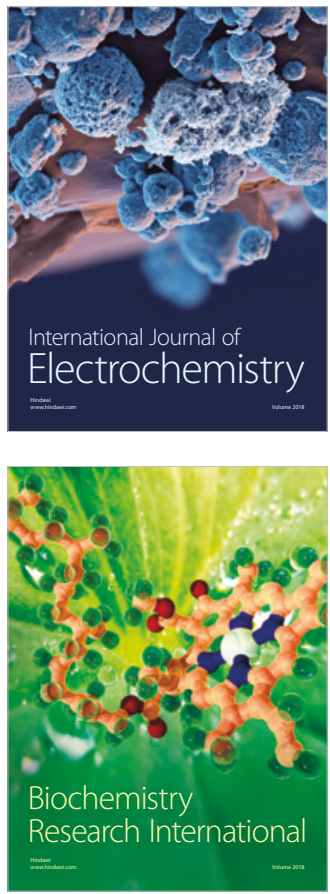